Research Article

\title{
Study on the Effect of Extra Pole Support on Seismic Resistance for Low-Rise RC Structures
}

\author{
Pengjie Lu (iD) ${ }^{1,2}$ and Guoxin Wang ${ }^{1,2}$ \\ ${ }^{1}$ State Key Laboratory of Coastal and Offshore Engineering, Dalian University of Technology, Dalian 116024, \\ Liaoning, China \\ ${ }^{2}$ Institute of Earthquake Engineering, School of Hydraulic Engineering, Faculty of Infrastructure Engineering, \\ Dalian University of Technology, Dalian 116024, Liaoning, China \\ Correspondence should be addressed to Pengjie Lu; lu_pengjie@outlook.com
}

Received 12 July 2019; Accepted 3 October 2019; Published 23 October 2019

Academic Editor: Eric Lui

Copyright (C) 2019 Pengjie Lu and Guoxin Wang. This is an open access article distributed under the Creative Commons Attribution License, which permits unrestricted use, distribution, and reproduction in any medium, provided the original work is properly cited.

\begin{abstract}
There is a common way to enhance the collapse safety of residential houses using extra tilted poles supporting poor structures from the outside before and/or after earthquakes in seismic regions, especially in rural areas. But, almost all of these supporting measures are still weak and lack of scientific design and evaluation. This study takes a poorly designed two-bay and three-story RC frame building as an object to explore the effect of this kind of support measures on structural seismic resistance by comparing with a standard-designed RC frame structure model as a contrastive case. The results obtained by performance-based methods indicate that extra poles can improve the seismic collapse safety and reduce structural seismic damage of the poorly designed structure (PDS) effectively. The median collapse capacity parameter $\theta$ increases from $1.31 \mathrm{~g}$ to the range of $1.92 \sim 2.39 \mathrm{~g}$, and $S_{\mathrm{a}}\left(T_{1} ; 10 \%\right)$ (spectral acceleration at the first-mode period which causes $10 \%$ probability of structural collapse) also increases from $0.57 \mathrm{~g}$ to the range of $0.75 \sim 1.08 \mathrm{~g}$. Study of dynamic structural damage shows a great damage reduction of PDS under seismic loads, especially $S_{\mathrm{a}}\left(T_{1}\right)=0.2 \mathrm{~g}$. This study proves that this simple measure can improve the seismic resistance of PDS into an acceptable level by taking our suggested practical and efficient supporting schemes.
\end{abstract}

\section{Introduction}

The seismic design has been a very important sector in civil engineering as earthquakes are devastating natural disasters, and serious losses of life and property can be made in a very short time [1]. Most cities and regions throughout the world have experienced devastating seismic events. Earthquakes have frequently occurred all over the world in recent years. The destruction and collapse of buildings is a major cause of loss of life and property in earthquake disasters.

A large number of postsurveys show that there are two main reasons for the collapse of building structures during the earthquake which are as follows [2].

First one is the weak seismic capacity caused by design or construction. For example, the Tangshan earthquake (July 28, 1976, China) caused 242,769 deaths and 164,851 serious injuries. One of the main reasons is that building codes at that time were based on the single-fortificationprinciple depending on basic seismic intensity, which only requires structural strength. This single-fortificationprinciple code was proved to be unable to guarantee the seismic capacity of the structure. Because the structure wants to have enough seismic capacity, it must meet the requirements of strength, stiffness, and ductility at the same time. China quickly adjusted the structural design code for the painful lessons of the earthquake. For the structure to have sufficient seismic capacity, it must meet the requirements of strength, stiffness, and ductility at the same time [3,4]. After this tragic event, building codes were updated very quickly.

The second reason is the greater seismic intensity than we expected. According to the data from the United States 
Geological Survey (USGS), there have been a large number of super earthquakes in recent years. As of May 20, 2019, 21 earthquakes with a magnitude greater than 7 have occurred worldwide since 2018. The largest of these was the 8.2 magnitude Fiji earthquake (August 2018). Many seismic events with higher magnitudes than the expected one have also demonstrated that many existing buildings are insufficient to resist these types of events in the past decades [5]. For example, the devastating Wenchuan earthquake (May 12, 2008, China) proved that buildings constructed strictly according to building codes at that time and with proper workmanship performed well with lower and acceptable collapse probability [2] during earthquakes. But, the Wenchuan earthquake still caused a loss of 69,226 people and a direct economic loss of 128 billion US dollars. The main reason is that the earthquake intensity of the Wenchuan earthquake greatly exceeded expectations.

It should be mentioned specially that about 90 percent of the collapsed buildings during the Wenchuan earthquake were distributed in rural areas. The Jiuzhaigou earthquake $\left(M_{\mathrm{s}} 7.0\right.$, August 8, 2017, China) has 76 completely collapsed structures, all in rural areas. This is because in rural areas, it is affected more seriously by the limitations of knowledge and the implementation of norms, so its disaster losses are more serious. In rural areas, there are more building structures that do not meet the seismic requirements because of the lack of materials and awareness. The existing of the massive number of insufficient and substandard structures brings fateful danger for human lives. This situation is even more serious in developing countries such as India, Pakistan, and China [6-8].

With the strengthening of aseismic awareness, it is realized that some measures need to be applied to protect and reduce the losses for people living. Structural strengthening technology and collapse safety assessment for the existing building have been developing rapidly in past decades $[3,4,9,10]$ However, the reinforcement of residential structures in rural areas is not widely applied because of the limited economic and technology.

Therefore, this paper gives the evaluation and support suggestions for simple support in rural areas in view of the weak seismic capacity of residential houses in rural areas. Performance-based structural analysis and evaluation methods are used to study the typical structural support schemes and the support effects and to know whether such simple support measures can improve the seismic performance of poorly designed structures, especially, if all of these supporting schemes can get positive answers, and then, corresponding effective support suggestions will be provided based on our series of research.

Performance-based design (PBD) idea has been widely recognized and applied since it was proposed in the $1990 \mathrm{~s}$ $[11,12]$. The performance-based theory has been widely used in structural design and seismic performance assessment. Nowadays, PBD engineering state-of-practice can be found in design codes of many countries such as FEMA-445 [13], ASCE-41 [14], ATC-58 [15], FEMA-P-58-
$1[16,17]$, and Chinese Standard [18]. Performance-based seismic evaluation methods of structures are mainly divided into static analysis and dynamic analysis. The nonlinear static analysis, also called pushover analysis, is an efficient method to estimate the seismic demand of buildings, which has gained great popularity and becomes a standard tool for seismic assessment in many codes of practice because of its simplicity and reasonable accuracy $[19,20]$. The nonlinear dynamic analysis method, also known as the nonlinear response time-history analysis (NLRHA) method, is considered as the most accurate method to evaluate the seismic response of buildings. Nevertheless, NLRHA is not suitable to be used for quick assessment of buildings because of the extremely heavy computational demand [19].

The simple measure in this study is using extra tilted poles to support a typical low-rising RC building in rural areas. A standard-designed structure (SDS) is constructed in this study based on the current building code [21] in a specific seismic region (Jiuzhai, Sichuan). And, a poorly designed RC structure (PDS) model is also built as an object of a substandard representative building in Chinese rural areas. Three groups of support schemes are designed to explore the influence of angle between poles and the ground, location and the number of poles, and the crosssection size on the improvement efficiency. Seismic collapse capacity and structural dynamic response are assessed to explore the impact of the extra tilted pole supporting. Further study of structural seismic damage is also carried out to investigate the influence of the extra devices on structural seismic resistance. Numerical analysis models of all structures are built on powerful nonlinear finite element analysis platform software, OpenSEES. Results of structural collapse capacity and damage index assessments can provide some scientific references for the strengthening design for PDSs.

\section{Structural Analysis Model}

2.1. RC Frame Buildings. This study takes a typical poorly designed RC frame structure (PDS) as an example of rural building structural to assess the impact of the tilted strutting poles on seismic resistance of the poor building. The standard-designed RC building (SDS) is designed basing on the current Chinese building code with a column cross section $400 \mathrm{~mm} \times 400 \mathrm{~mm}$.

This three-story two-bay RC frame structure is one of the most typical civil house structures in Chinese rural regions, the model of which is created by using the OpenSEES structural analysis platform. PDS and SDS have the same structural plane and elevation layout as illustrated in Figure 1. The reinforcement configurations of beams and columns of PDS are illustrated in Figure 2(a). The column of PDS is not meeting the building code requirements, cross section $(300 \mathrm{~mm} \times 300 \mathrm{~mm})$ of which is smaller than the standard designed one $(400 \mathrm{~mm} \times 400 \mathrm{~mm})$. Figure 2(b) illustrates the rebars and shape of the sections of the column of SDS. Element modeling consists of nonlinear beamcolumn elements and beamWithHinges elements [22], both 


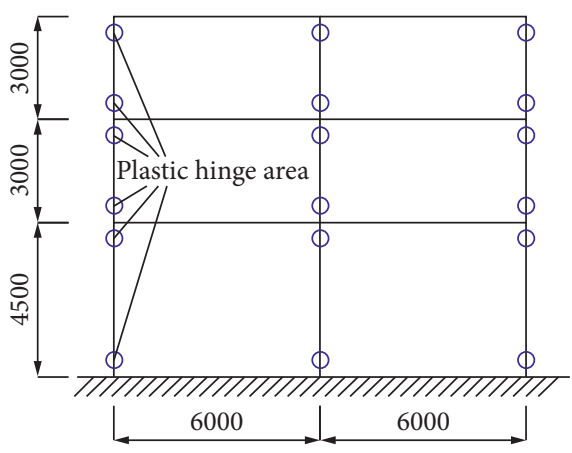

(a)

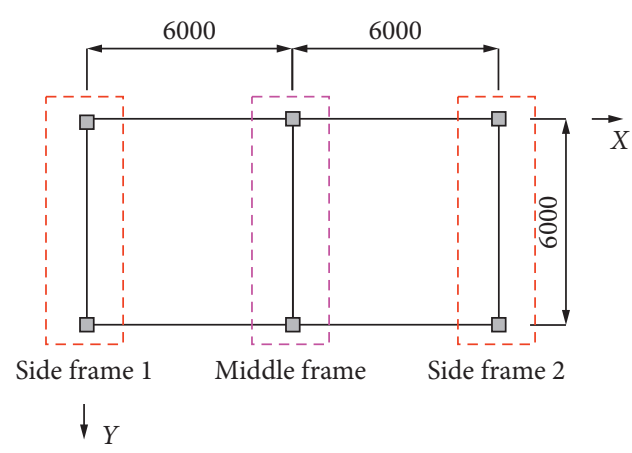

(b)

Figure 1: (a) Floor plan of the poorly designed RC building. (b) Layout of columns.

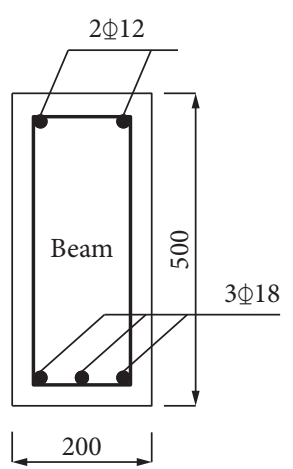

(a)

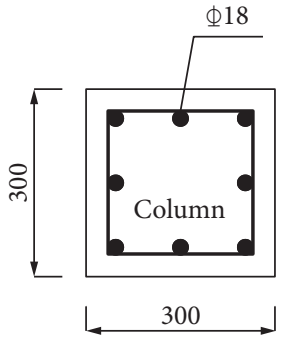

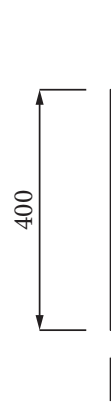

(b)

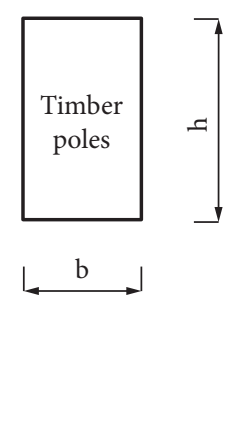

(c)

Figure 2: (a) Reinforcement configurations of beams and columns of PDS; (b) reinforcement configurations of columns of SDS; (c) parameters of timber pole cross section.

of which are force-based elements. Rayleigh damping corresponding to $5 \%$ of critical damping in the first and second modes is applied. The floor slabs are assumed to be rigid, so the beams are constructed as nonlinear beam-column elements while the columns are constructed as beamWithHinges elements as shown in Figure 1(a). The plastic hinge length is specified using an empirically validated relationship as follows [23]:

$$
l_{\mathrm{p}}=0.08 L+0.022 f_{\mathrm{y}} d
$$

where $L$ represents the length of the member, $f_{\mathrm{y}}$ is the yield strength of the longitudinal reinforcing bars, and $d$ is the diameter. The collapse capacities of the building are evaluated by using a performance-based methodology which will be illustrated in the following section.

The concrete material is the Concrete 02 [24] Material in OpenSEES, which is a uniaxial concrete material object with tensile strength and linear tension softening with compressive strength $f_{\mathrm{pc}}=26.8 \mathrm{MPa}$, crushing strength $f_{\mathrm{pcu}}=10 \mathrm{MPa}$, and tensile strength $f_{\mathrm{t}}=2.2 \mathrm{MPa}$. The strain at compressive strength epsc0 is 0.0015 in this case, while the strain at crushing strength is -0.0033 . Tension softening stiffness $E_{\mathrm{ts}}$ (slope of the linear tension soft- ening branch) is $1100 \mathrm{MPa}$. The steel material model is the Steel 02 [24] Material in OpenSEES, which is a uniaxial Giuffre-Menegotto-Pinto model steel material object with isotropic strain hardening. The yield strength $F_{\mathrm{y}}$ is $400 \mathrm{MPa}$, and the initial elastic tangent $E$ is $206000 \mathrm{MPa}$. The cyclic stress-strain behavior of concrete and steel is shown in Figure 3 [24]. Referring to the widely used support measure for a poorly designed building, this study analyses one of the most popular support forms, as shown in Figure 4. Wood is considered to be anisotropic as the basic physical and mechanical properties vary along the longitudinal, radial, and tangential planes. For purposes of analysis, timber material behavior can be simplified into an elastic perfectly-plastic material [25] with a tangent modulus $E$ of $116000 \mathrm{MPa}$, a plastic state strain in the tension of 0.0021 , and a plastic state strain in compression of 0.0014 . The constitutive parameters are selected according to the European Standard EN 1194 [26].

The element used in this study is the timber pole with a rectangular cross-section, edge length of which is shown in Figure 2(b). Five sets of different edge lengths are considered as illustrated in Table 1 to study the effects of different extra pole section size support. 


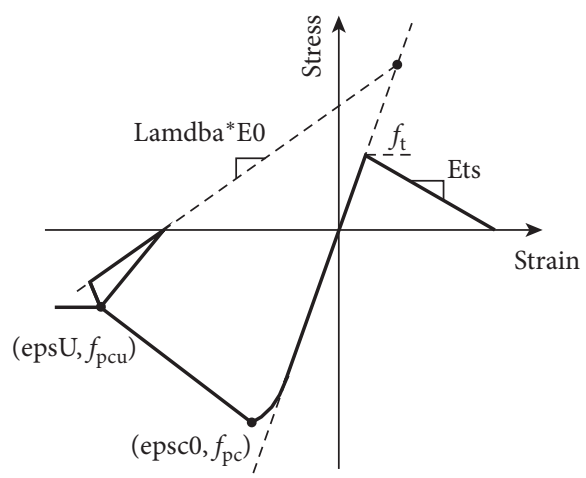

(a)

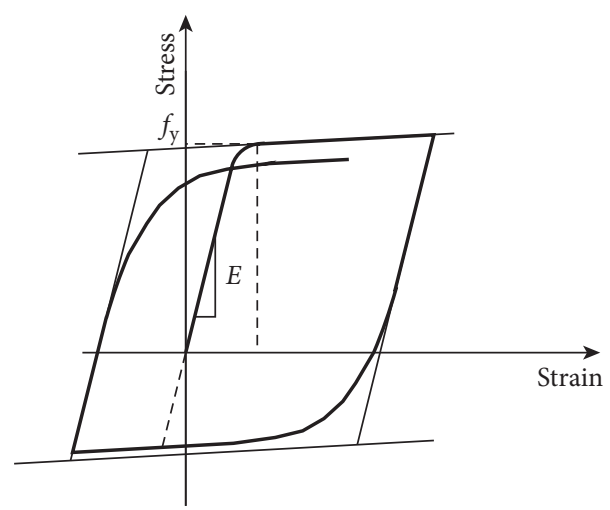

(b)

Figure 3: Illustration of material constitutive relation: (a) concrete and (b) steel.

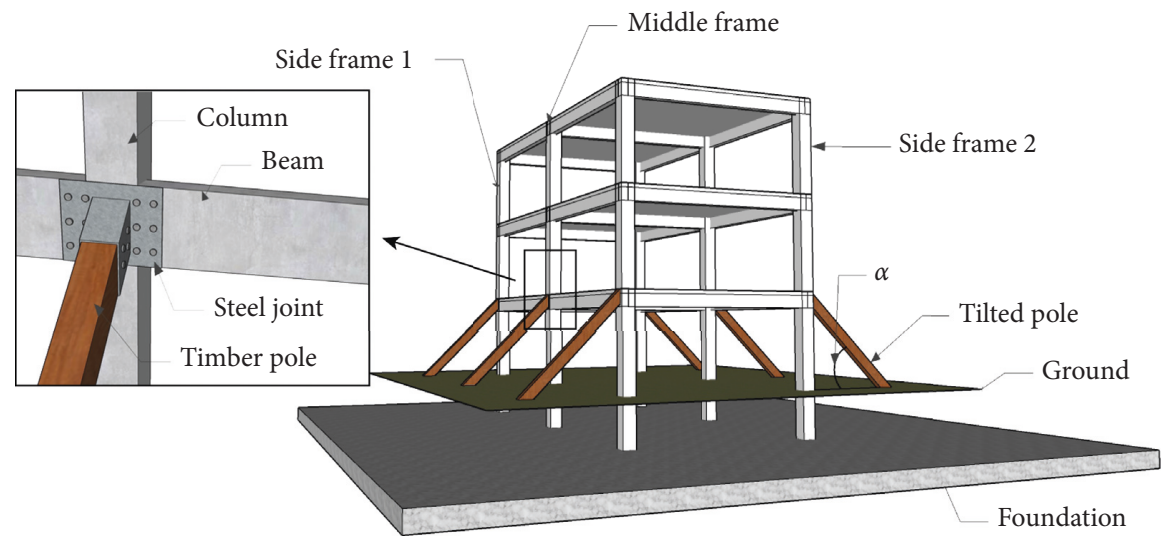

FIGURE 4: Schematic of support scheme.

TABLE 1: Cross-section parameters of timber poles.

\begin{tabular}{llllll}
\hline Parameters & C0 & C1 & C2 & C3 & C4 \\
\hline B & 200 & 200 & 200 & 100 & 100 \\
H & 300 & 200 & 100 & 150 & 100
\end{tabular}

2.2. Supporting Schemes. In order to study the different impact factors on the supporting effect, two scenarios of support schemes are designed to explore the impacts of support location, the number of support poles, and the angle between the tilted poles and the horizontal ground. The detail information is shown in Table 2.

Group $\mathrm{A}$ is aimed at the angle $(\alpha)$ between the tilted strutting pole and the horizontal ground, as shown in Figure 3. Five different schemes are designed with $\alpha$ ranging from $30^{\circ}$ to $72^{\circ}$ to study the impact of angle $(\alpha)$ on collapse safety improvement efficiency. The joints between the poles and the ground are simplified as hinges, while the poles are fixed to the structure. Meanwhile, group $\mathrm{N}$ is aimed to explore the impact of supporting location and the number of poles on improving the efficiency of structural seismic resistance. The RC frame building is divided into three parts: side frame 1, middle frame, and side frame 2, as illustrated in Figure 1(b). Tilted poles are all placed with a $45^{\circ}$ angle to the horizontal ground to study the impact of locations and numbers of the poles. Four strengthening schemes are involved: two of them are the cases with two out of three frames supported $(\mathrm{N} 1, \mathrm{~N} 2)$; the other two schemes are the cases with only one frame supported (N3, N4). Group S is aimed at the effects of the cross-section size of the timber poles. In this group, all frames are supported with tilted poles placed with a $45^{\circ}$ angle to the horizontal ground. Crosssection sizes of different schemes are illustrated in Table 1, selected based on the material properties.

\section{Methodology}

Performance-based design (PBD) framework was presented throughout the past couple of decades to increasing structural safety against nondeterministic seismic hazards. In accordance with performance-based earthquake engineering, the structures need to be able to resist various earthquake loading scenarios in a measurable fashion and sustain potential damages corresponding to desired performance levels [27].

3.1. Pushover Analysis. Pushover analysis is an efficient nonlinear static method to estimate the seismic demand of buildings. It is a performance-based method where a set of equivalent lateral forces is applied to the structures to obtain 
TABLE 2: Support schemes and the parameters of the fragility functions.

\begin{tabular}{|c|c|c|c|c|c|c|}
\hline \multicolumn{2}{|l|}{ Structures } & $\alpha$ & Cross section & Side frame 1 & Middle frame & Side frame 2 \\
\hline \multicolumn{2}{|c|}{$\begin{array}{l}\text { Poorly designed } \\
\text { structure (PDS) }\end{array}$} & - & - & - & - & - \\
\hline \multicolumn{2}{|c|}{$\begin{array}{l}\text { Standard-designed } \\
\text { structure (SDS) }\end{array}$} & - & - & - & - & - \\
\hline \multirow{5}{*}{ Group A } & A1 & $30^{\circ}$ & $\mathrm{C} 0$ & $\sqrt{ }$ & $\sqrt{ }$ & $\sqrt{ }$ \\
\hline & A2 & $37^{\circ}$ & $\mathrm{CO}$ & $\sqrt{ }$ & $\sqrt{ }$ & $\sqrt{ }$ \\
\hline & A3 & $45^{\circ}$ & $\mathrm{CO}$ & $\sqrt{ }$ & $\sqrt{ }$ & $\sqrt{ }$ \\
\hline & A4 & $60^{\circ}$ & $\mathrm{C} 0$ & $\sqrt{ }$ & $\sqrt{ }$ & $\sqrt{ }$ \\
\hline & A5 & $72^{\circ}$ & $\mathrm{CO}$ & $\sqrt{ }$ & $\sqrt{ }$ & $\sqrt{ }$ \\
\hline \multirow{4}{*}{ Group N } & N1 & $45^{\circ}$ & $\mathrm{C} 0$ & $\sqrt{ }$ & $\sqrt{ }$ & - \\
\hline & $\mathrm{N} 2$ & $45^{\circ}$ & $\mathrm{C} 0$ & $\sqrt{ }$ & - & $\sqrt{ }$ \\
\hline & N3 & $45^{\circ}$ & $\mathrm{CO}$ & - & $\sqrt{ }$ & - \\
\hline & N4 & $45^{\circ}$ & $\mathrm{CO}$ & $\sqrt{ }$ & - & - \\
\hline \multirow{4}{*}{ Group S } & $\mathrm{S} 1$ & $45^{\circ}$ & $\mathrm{C} 1$ & $\sqrt{ }$ & $\sqrt{ }$ & $\sqrt{ }$ \\
\hline & S2 & $45^{\circ}$ & $\mathrm{C} 2$ & $\sqrt{ }$ & $\sqrt{ }$ & $\sqrt{ }$ \\
\hline & S3 & $45^{\circ}$ & $\mathrm{C} 3$ & $\sqrt{ }$ & $\sqrt{ }$ & $\sqrt{ }$ \\
\hline & S4 & $45^{\circ}$ & $\mathrm{C} 4$ & $\sqrt{ }$ & $\sqrt{ }$ & $\sqrt{ }$ \\
\hline
\end{tabular}

" $\sqrt{ }$ " indicates supported and "-" indicates no support.

the strength and ductility demand of the structure. The pushover method has gained great popularity and becomes a standard tool for seismic assessment in many codes of practice $[28,29]$ owing to its simplicity and reasonable accuracy. In this study, the pushover analysis is performed to estimate the damage level of structures, which will be explained later.

3.2. Time-History Analysis. Time-history analysis means a much larger amount of computation than static analysis. But, it can capture the structural response more accurately under seismic loads. Time-history analysis has been recommended to use in most of the codes of practice for seismic design $[28,29]$.

Time-history analysis is used to determine the response of the structure due to ground motion with a certain intensity level. In this study, nonlinear response history analysis is performed for the forty selected ground motions to study the structural seismic performance. The parameters that are taken into account are the interstory drift ratio as the structural damage measure and spectral acceleration $(\xi=5 \%$ damped) at the structural first-mode period $\left(S_{\mathrm{a}}\left(T_{1}\right)\right)$ [30] as the ground motion intensity measure.

IDA is a widely used parametric analysis method to perform nonlinear dynamic structural analyses. Its results are expressed by IDA curves, which show the relationship between the ground motion intensity (IM, intensity measure) and the structural response (DM, damage measure) [31-34]. Structural response parameterized (structure damage measure, $\mathrm{DM}$ ) is represented by the peak interstory drift ratio $\left(\theta_{\max }\right)$. Spectral acceleration $(\xi=5 \%$ damped $)$ at the structural first-mode period $\left(S_{\mathrm{a}}\left(T_{1}\right)\right)$ is selected as the ground motion intensity measure [30] in this study. Ground motion records are selected and scaled without considering the distinctive spectral shape of rare (extreme) ground motions. Ground motion records are amplitude scaled according to the spectral acceleration at the first-mode period, $S_{\mathrm{a}}\left(T_{1}\right)$, until collapse happens. IDA curves are obtained with linear interpolation.

Generally, structural collapse is defined as the point of dynamic instability, where the lateral story drifts of the building increase without bounds, normally called sideway collapse [3], which occurs when the IDA curve becomes flat in shape. The capacity point divides an IDA curve into two regions, i.e., noncollapse one (lower IM) and another collapse one (higher IM). There are two basic rules to define the collapse limit-state on an IDA curve. One is based on damage measure (DM-based rule), and the other one is based on the ground motion intensity measure (IMbased rule). The DM-based rule is generated from a statement of the format: "If $\mathrm{DM} \geq C_{\mathrm{DM}}$, then the limit-state is exceeded." In this study, the limit-state $C_{\mathrm{DM}}$ is defined as $\theta_{\max }=10 \%$ [35]. The IM-based rule is generated by a statement of the form: "If $\mathrm{IM} \geq C_{\mathrm{IM}}$, then the limit-state is exceeded." The IM-based rule defines the capacity point as the last point on the curve with a tangent slope equal to $\lambda$ $(\lambda<1$, Federal Emergency Management Agency recommends 20\% [35]) of the elastic slope. In this paper, a procedure combined with these two rules is used to get the collapse capacity points. In order to be conservative, the lowest point (in IM terms) is considered as the capacity point.

3.3. Collapse Fragility Assessment. The structural collapse capacity is assessed by using a performance-based methodology. IDA is used to organize the nonlinear dynamic analyses of structures to the ground motion records selected from the Pacific Earthquake Engineering Research Center (PEER) database. The structural collapse capacity is assessed by using a fragility function, which is fitted with IDA results.

Fragility curves are commonly used in seismic risk analysis, reflecting the probability of structural collapse under different ground motion intensities [36-38]. A 
fragility function is often defined by a lognormal cumulative distribution function:

$$
P(\text { collapse } \mid \mathrm{IM}=x)=\Phi\left(\frac{\ln (x / \theta)}{\beta}\right),
$$

where $P$ (collapse $\mid \mathrm{IM}=x)$ is the probability that a ground motion with IM $=x$ will cause the structure to collapse, $\Phi($ ) is the standard normal cumulative distribution function, $\theta$ is the median of the fragility function (the IM level with $50 \%$ probability of collapse), and $\beta$ is the natural logarithm standard deviation of IM.

Equation (1) implies that the IM values of ground motions causing the collapse of a given structure are distributed lognormally; parameters $\theta$ and $\beta$ can be estimated from data collected by nonlinear analysis. In this paper, the data come from the IDA results by inputting a set of selected ground motion records. Each ground motion is individually applied to structural models by using the IDA approach to get IDA curves. A series of collapse capacity points $\left(\mathrm{IM}_{i}\right)$ are generated from the IDA analysis, which is the observed data for the fragility function. Parameters $(\theta$ and $\beta)$ can be estimated by using the following equations:

$$
\begin{aligned}
& \widehat{\theta}=\frac{1}{n} \sum_{i=1}^{n} \ln \left(\mathrm{IM}_{i}\right), \\
& \widehat{\beta}=\left(\frac{1}{n} \sum_{i=1}^{n}\left(\ln \left(\mathrm{IM}_{i}\right)-\widehat{\theta}\right)^{2}\right)^{1 / 2},
\end{aligned}
$$

where $\mathrm{IM}_{i}$ is the observed capacity point of no. $i$ ground motion record; there are $n$ ground motion records in total, $\hat{\theta}$ is the logarithmic mean value of IM, and $\widehat{\beta}$ is the corresponding logarithmic standard deviation.

3.4. Damage Assessment. The approach to evaluating the damage in this study is performing two pushover analyses, before and after subjecting the structure to an earthquake. The structural damage index (DI) is evaluated using the following equation [39]:

$$
\mathrm{DI}=1-\frac{K_{\text {final }}}{K_{\text {initial }}},
$$

where $K_{\text {initial }}$ is the initial slope of the base shear-top deflection relationship resulting from the pushover analysis of the frame before subjecting it to the earthquake ground motion and $K_{\text {final }}$ is the initial slope of the same relationship but after subjecting the frame to the earthquake time history. This DI is applicable to both ductile structures and nonductile structures. The values of the DIs range from zero to one depending on the amount of damage experienced. A value of zero represents no damage while a damage index value of one corresponds to total collapse.

The inverted triangular distribution load is used in the pushover analyses for structures. It needs to be pointed out that the structure should be returned to the unloaded static state before performing the second pushover analysis. A gap of $50 \mathrm{~s}$ is added to the seismic load time history [40] in this study to make sure structures are returned to the unloaded static state after seismic loads.

\section{Incremental Dynamic Analysis}

4.1. Ground Motion Records. In this paper, forty ground motion records are selected from the strong ground motion database of the Pacific Earthquake Engineering Research Center (PEER). The selected strong ground motions have moment magnitudes $\left(M_{\mathrm{w}}\right)$ ranging from 6.0 to 8.0. The soil type for the site is on firm soil (with relatively high average shear wave velocity $(370-570 \mathrm{~m} / \mathrm{s}$ ) on top $30 \mathrm{~m}$ surface soil). Detail information of the records is listed in Table 3.

4.2. Performance of Incremental Dynamic Analysis. This section gives the IDA results that can provide corresponding collapse capacity points. The IDA results of poorly designed structure (PDS), standard-designed structure (SDS), and 13 supporting schemes are presented in Figure 5, respectively. The dots on the curves are the corresponding collapse capacity points for each ground motion. It can be seen that all the IDA curves are all in the typical IDA curve form. IDA curves differ with the ground motions, which are due to the different ground motion features. The fact that IDA results of different cases are different from each other indicates that the different support schemes affect the structural collapse capacity to different degrees. The detailed analysis of the effect of different support schemes will be carried out later.

\section{Seismic Performance}

Structural seismic responses under different ground motion intensities are analyzed to explore the effect of different support schemes on structural seismic performance. Three different ground motion intensities $\left(S_{\mathrm{a}}\left(T_{1}\right)=0.1 \mathrm{~g}, 0.2 \mathrm{~g}\right.$, and $0.4 \mathrm{~g})$ are selected in this study. Figure 6 and Table 4 illustrate the average of peak interstory drift ratio $\left(\theta_{\max }\right)$ of each floor under these three different ground motion intensities of group A, N, and S, respectively, beside with PDS and SDS. It can be observed that supporting schemes limit structural seismic response effectively as the peak interstory drift ratios of the first and second floors are obviously reduced from the PDS. From the data in Table 4, it can be seen that the peak interstory drift ratio $\left(\theta_{\max }\right)$ of PDS under the three different earthquake intensities are $0.32 \%, 0.75 \%$, and $4.17 \%$, respectively, which of SDS is $0.17 \%, 0.36 \%$, and $0.89 \%$. Peak interstory drift ratio $\left(\theta_{\max }\right)$ of supported structures under three different intensity earthquakes are $0.23 \% \sim 0.32 \%$, $0.52 \% \sim 0.71 \%$, and $1.2 \% \sim 1.58 \%$, respectively. It can be seen that the structural response of PDS is greatly reduced, and the different structural responses are quite obvious.

5.1. Group A. From Figure 6(a), it can be seen that the structural response of group $A$ is much lower than that of PDS under these three seismic intensity loads. Peak interstory drift ratios $\left(\theta_{\max }\right)$ of PDS are $0.32 \%, 0.75 \%$, and $4.17 \%$, respectively, in the bottom floor, while that of group $\mathrm{A}$ is reduced to $0.23 \% \sim 0.27 \%, 0.52 \% \sim 0.58 \%$, and $1.24 \% \sim 1.28 \%$ 
TABLE 3: Basic information of the ground motion records.

\begin{tabular}{|c|c|c|c|c|c|}
\hline No. & Earthquake & Year & Station & $M_{\mathrm{w}}$ & $\mathrm{Vs}_{30}(\mathrm{~m} / \mathrm{s})$ \\
\hline 1 & Parkfield & 1966 & Cholame-Shandon Array \#12 & 6.19 & 408.9 \\
\hline 2 & Parkfield & 1966 & San Luis Obispo & 6.19 & 493.5 \\
\hline 3 & San Fernando & 1971 & Castaic-Old Ridge Route & 6.61 & 450.3 \\
\hline 4 & San Fernando & 1971 & Lake Hughes \#12 & 6.61 & 602.1 \\
\hline 5 & Imperial Valley-06 & 1979 & Chihuahua & 6.53 & 274.5 \\
\hline 6 & Imperial Valley-06 & 1979 & Cucapah & 6.53 & 274.5 \\
\hline 7 & Coalinga-01 & 1983 & Parkfield-Cholame 2E & 6.36 & 522.7 \\
\hline 8 & Coalinga-01 & 1983 & Parkfield-Cholame 3E & 6.36 & 397.4 \\
\hline 9 & Coalinga-01 & 1983 & Parkfield-Fault Zone 10 & 6.36 & 372.7 \\
\hline 10 & Coalinga-01 & 1983 & Parkfield-Fault Zone 9 & 6.36 & 372.3 \\
\hline 11 & Coalinga-01 & 1983 & Parkfield-Gold Hill 5W & 6.36 & 441.4 \\
\hline 12 & Coalinga-01 & 1983 & Parkfield-Vineyard Cany 4W & 6.36 & 386.2 \\
\hline 13 & Coalinga- 01 & 1983 & Parkfield-Vineyard Cany 6W & 6.36 & 392.2 \\
\hline 14 & Superstition Hills-02 & 1987 & Parachute Test Site & 6.54 & 348.7 \\
\hline 15 & Superstition Hills-02 & 1987 & Superstition Mtn Camera & 6.54 & 362.4 \\
\hline 16 & Loma Prieta & 1989 & Coyote Lake Dam (SW Abut) & 6.93 & 597.1 \\
\hline 17 & Loma Prieta & 1989 & Gilroy-Historic Bldg. & 6.93 & 338.5 \\
\hline 18 & Loma Prieta & 1989 & Hollister-South \& Pine & 6.93 & 370.8 \\
\hline 19 & Loma Prieta & 1989 & Sunnyvale-Colton Ave. & 6.93 & 267.7 \\
\hline 20 & Landers & 1992 & Joshua Tree & 7.28 & 379.3 \\
\hline 21 & Landers & 1992 & Lucerne & 7.28 & 684.9 \\
\hline 22 & Northridge-01 & 1994 & LA-Baldwin Hills & 6.69 & 297.1 \\
\hline 23 & Northridge-01 & 1994 & LA-UCLA Grounds & 6.69 & 398.4 \\
\hline 24 & Northridge-01 & 1994 & Moorpark-Fire Sta & 6.69 & 405.2 \\
\hline 25 & Northridge-01 & 1994 & N Hollywood-Coldwater Can & 6.69 & 446.0 \\
\hline 26 & Northridge-01 & 1994 & San Gabriel-E Grand Ave & 6.69 & 401.4 \\
\hline 27 & Kobe, Japan & 1995 & Kakogawa & 6.9 & 312.0 \\
\hline 28 & Kobe, Japan & 1995 & Nishi-Akashi & 6.9 & 609.0 \\
\hline 29 & Kocaeli, Turkey & 1999 & Yarimca & 7.51 & 297.0 \\
\hline 30 & Chi-Chi, Taiwan & 1999 & CHY080 & 7.62 & 553.4 \\
\hline 31 & Chi-Chi, Taiwan & 1999 & TCU052 & 7.62 & 579.1 \\
\hline 32 & Chi-Chi, Taiwan & 1999 & TCU071 & 7.62 & 624.9 \\
\hline 33 & Chi-Chi, Taiwan & 1999 & TCU072 & 7.62 & 468.1 \\
\hline 34 & Chi-Chi, Taiwan & 1999 & TCU082 & 7.62 & 472.8 \\
\hline 35 & Chi-Chi, Taiwan & 1999 & TCU084 & 7.62 & 553.4 \\
\hline 36 & Chi-Chi, Taiwan & 1999 & TCU089 & 7.62 & 553.4 \\
\hline 37 & Chi-Chi, Taiwan & 1999 & TCU102 & 7.62 & 714.3 \\
\hline 38 & Duzce, Turkey & 1999 & Duzce & 7.14 & 276.0 \\
\hline 39 & Duzce, Turkey & 1999 & Lamont 375 & 7.14 & 424.8 \\
\hline 40 & Hector Mine & 1999 & Hector & 7.13 & 684.9 \\
\hline
\end{tabular}

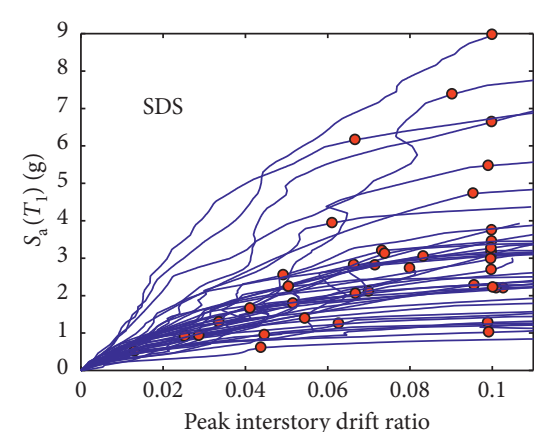

(a)

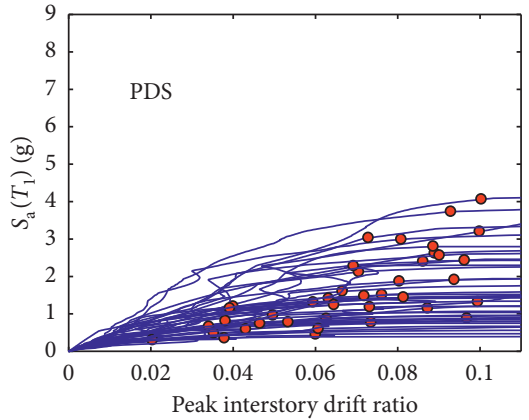

(b)

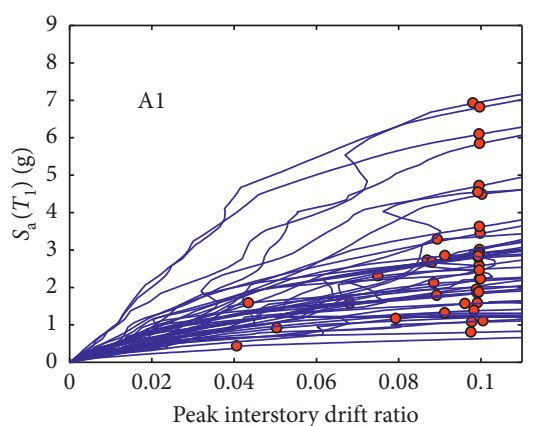

(c)

Figure 5: Continued. 


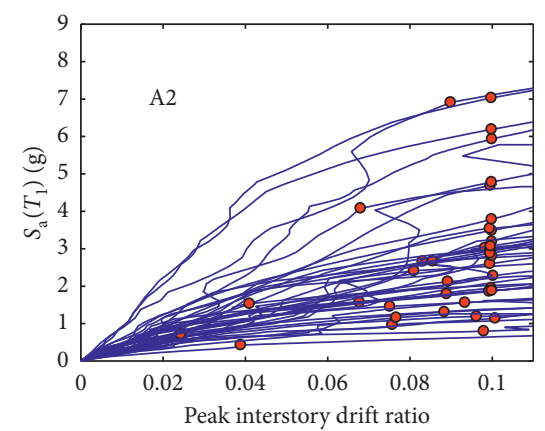

(d)

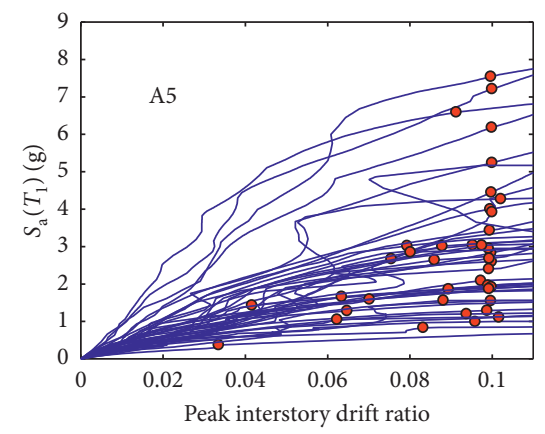

(g)

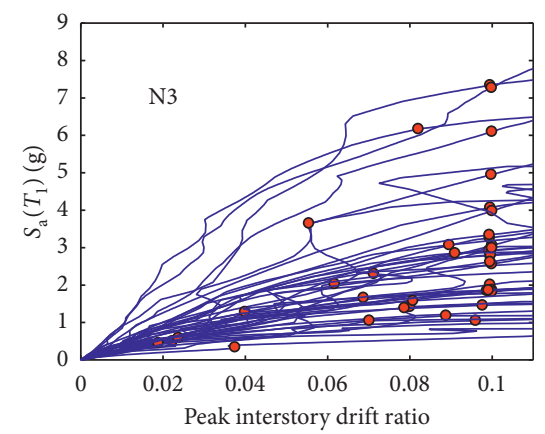

(j)

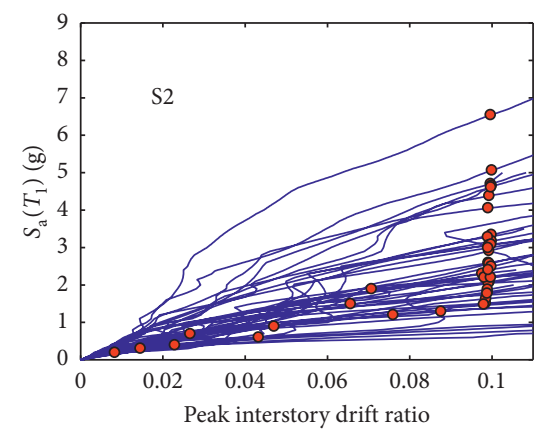

(m)

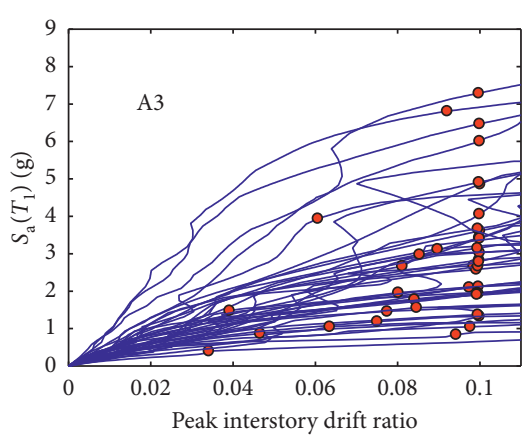

(e)

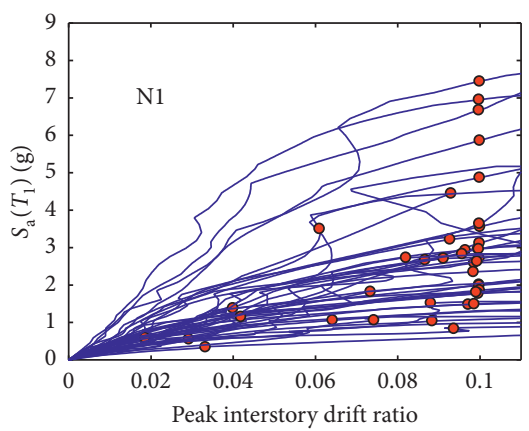

(h)

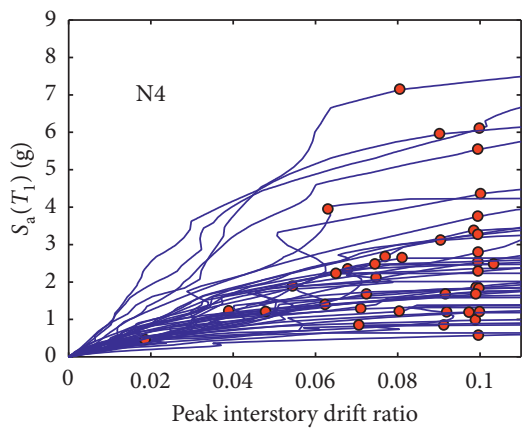

(k)

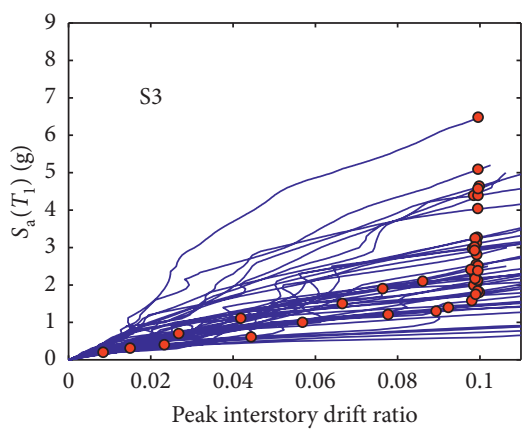

(n)

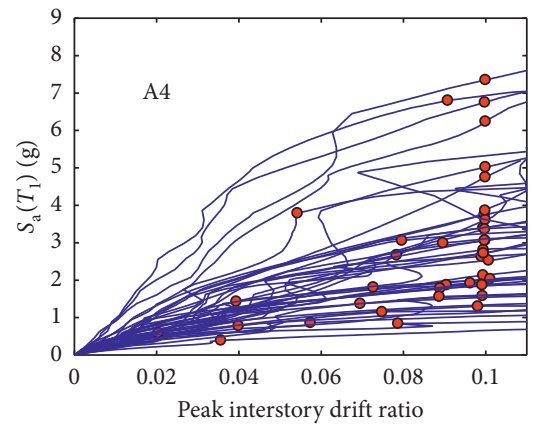

(f)

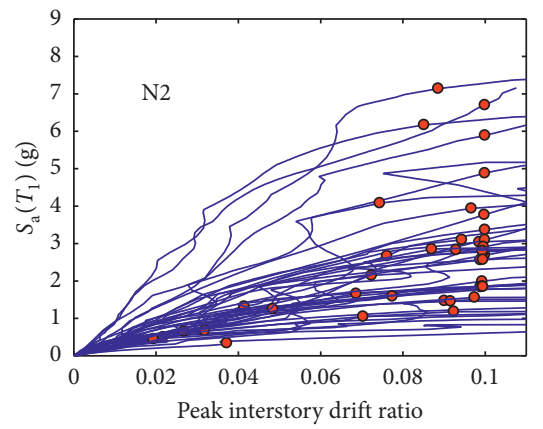

(i)

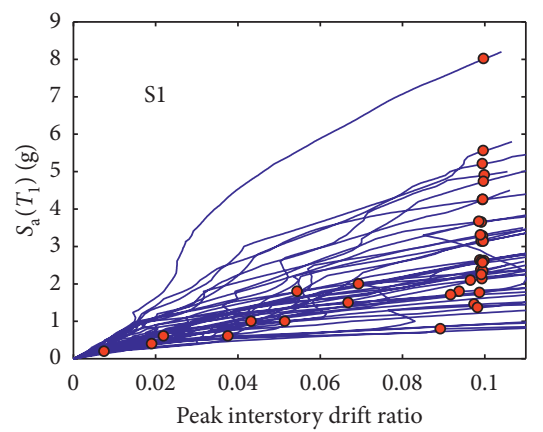

(1)

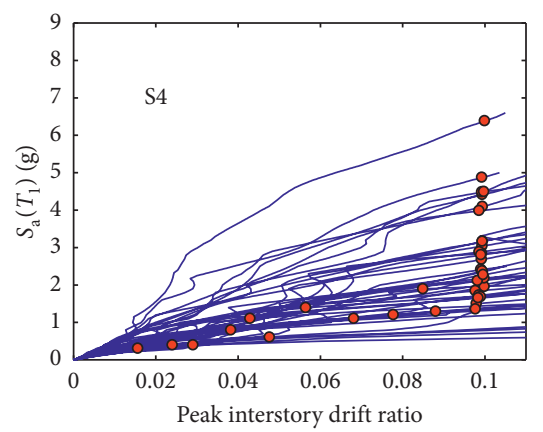

(o)

FIGURE 5: IDA curves of the poor building and different support schemes.

under seismic loads with $S_{\mathrm{a}}\left(T_{1}\right)=0.1 \mathrm{~g}, 0.2 \mathrm{~g}, 0.4 \mathrm{~g}$, respectively. The structural response decreases as expected. But, $\theta_{\max }$ of group $\mathrm{A}$ is still larger than that of SDS. Comparing the five cases of group $A$, it can be seen that the larger the angle between the extra poles and the horizontal ground, the smaller the structural response.
5.2. Group $N$. The peak interstory drift ratios of group $\mathrm{N}$ under three seismic intensity loads $\left(S_{\mathrm{a}}\left(T_{1}\right)=0.1 \mathrm{~g}, 0.2 \mathrm{~g}\right.$, $0.4 \mathrm{~g}$ ) are $0.27 \%, 0.58 \% \sim 0.61 \%$, and $1.28 \% \sim 1.36 \%$, lower than those of PDS obviously. The support schemes of group $\mathrm{N}$ also effectively reduce the seismic response of PDS as expected. The seismic response of four cases in group $\mathrm{N}$ is 


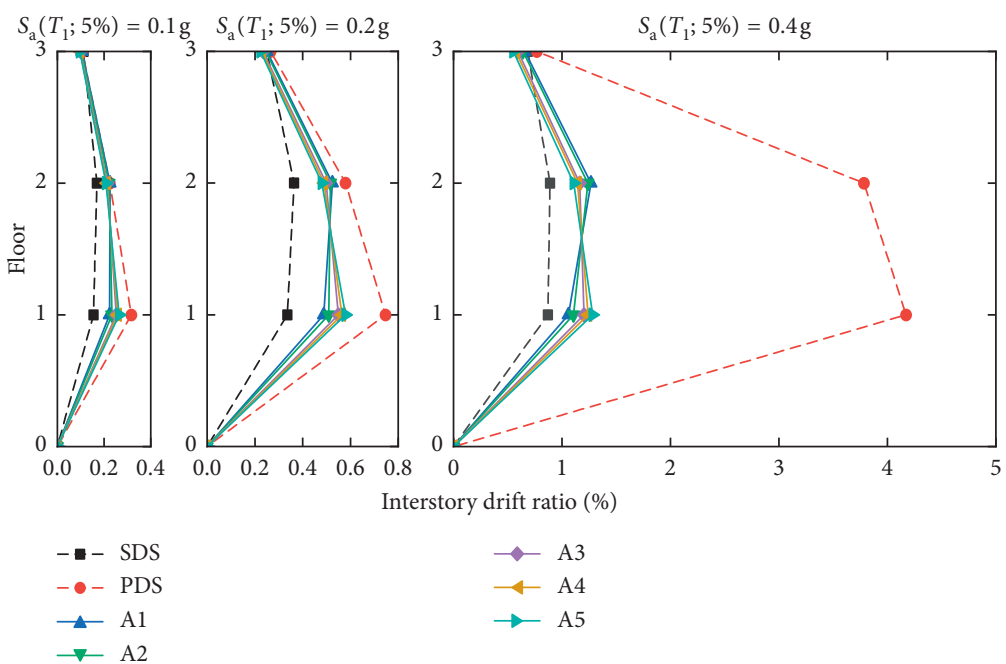

(a)
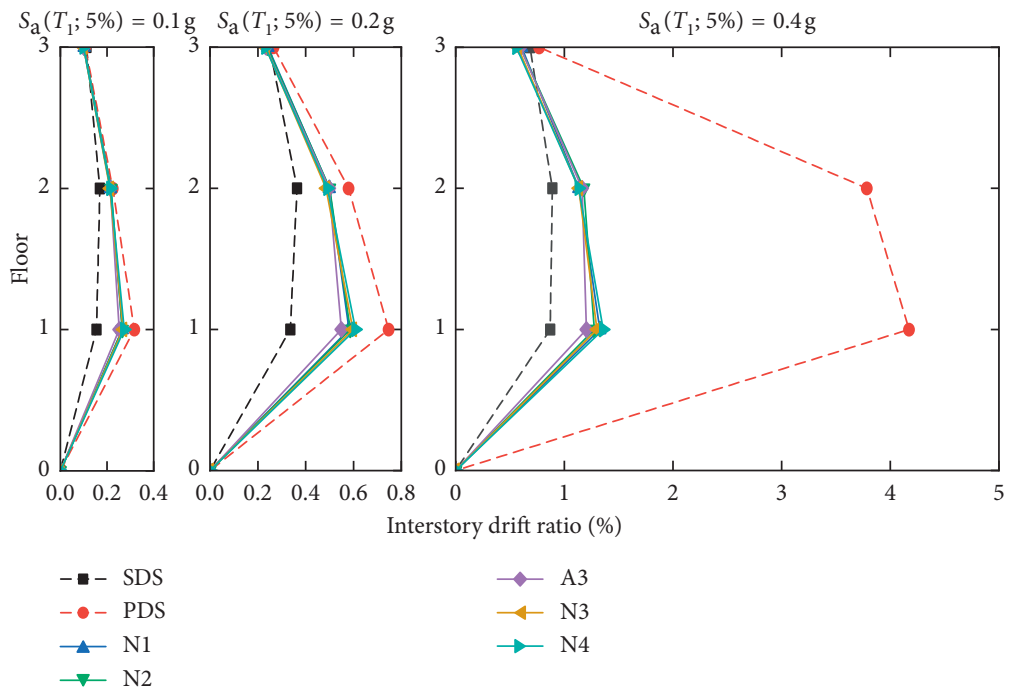

$\rightarrow \mathrm{N} 4$

(b)
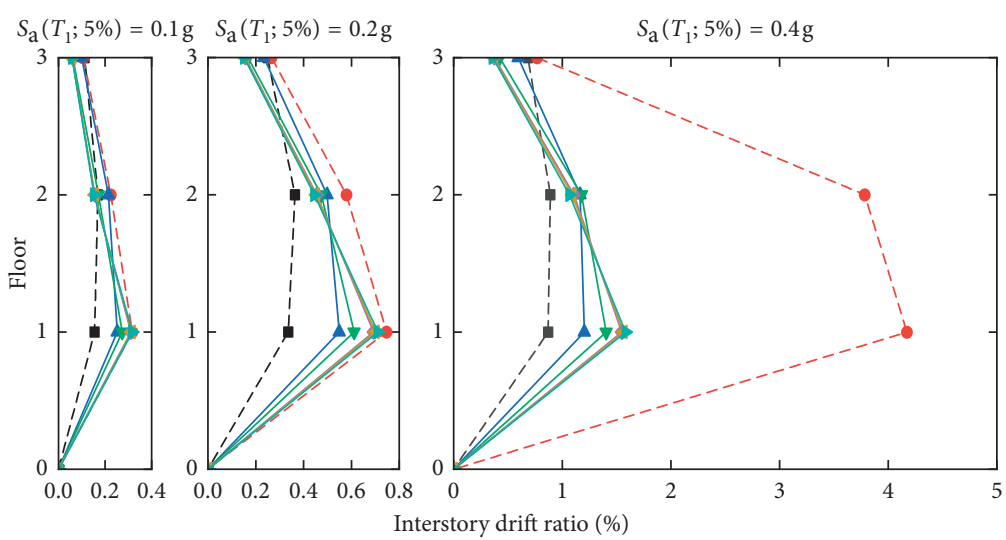

-- SDS
-- PDS
- A3
$\square$ S1

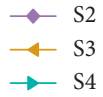

(c)

FIGURE 6: Average of the peak interstory drift ratio of each floor. 
TABle 4: Peak interstory drift ratio/\%.

\begin{tabular}{lcccccccccc}
\hline IM & & \multicolumn{3}{c}{$S_{\mathrm{a}}\left(T_{1}\right)=0.1 \mathrm{~g}$} & \multicolumn{3}{c}{$S_{\mathrm{a}}\left(T_{1}\right)=0.2 \mathrm{~g}$} & \multicolumn{3}{c}{$S_{\mathrm{a}}\left(T_{1}\right)=0.4 \mathrm{~g}$} \\
\hline Floor & & 1 & 2 & 3 & 1 & 2 & 3 & 1 & 2 & 3 \\
SDS & & 0.16 & 0.17 & 0.11 & 0.34 & 0.36 & 0.25 & 0.87 & 0.89 & 0.69 \\
PDS & & 0.32 & 0.23 & 0.11 & 0.75 & 0.58 & 0.27 & 4.17 & 3.78 & 0.77 \\
& $\mathrm{~A} 1$ & 0.22 & 0.23 & 0.11 & 0.49 & 0.53 & 0.25 & 1.06 & 1.27 & 0.66 \\
Group & $\mathrm{A} 2$ & 0.23 & 0.22 & 0.1 & 0.51 & 0.52 & 0.25 & 1.11 & 1.24 & 0.64 \\
A & A3 & 0.25 & 0.22 & 0.1 & 0.55 & 0.5 & 0.23 & 1.2 & 1.16 & 0.59 \\
& A4 & 0.26 & 0.21 & 0.1 & 0.56 & 0.49 & 0.23 & 1.24 & 1.14 & 0.58 \\
& A5 & 0.27 & 0.21 & 0.1 & 0.58 & 0.48 & 0.22 & 1.28 & 1.11 & 0.55 \\
& N1 & 0.27 & 0.22 & 0.1 & 0.58 & 0.5 & 0.24 & 1.33 & 1.13 & 0.61 \\
Group & N2 & 0.27 & 0.22 & 0.1 & 0.59 & 0.5 & 0.24 & 1.28 & 1.18 & 0.59 \\
N & N3 & 0.27 & 0.21 & 0.1 & 0.6 & 0.49 & 0.23 & 1.3 & 1.13 & 0.57 \\
& N4 & 0.27 & 0.22 & 0.1 & 0.61 & 0.49 & 0.23 & 1.36 & 1.13 & 0.56 \\
& S1 & 0.28 & 0.17 & 0.07 & 0.61 & 0.47 & 0.17 & 1.4 & 1.18 & 0.42 \\
Group & S2 & 0.31 & 0.16 & 0.06 & 0.69 & 0.45 & 0.16 & 1.55 & 1.1 & 0.38 \\
& S3 & 0.31 & 0.15 & 0.06 & 0.7 & 0.45 & 0.15 & 1.56 & 1.09 & 0.37 \\
& S4 & 0.32 & 0.15 & 0.06 & 0.71 & 0.45 & 0.15 & 1.58 & 1.07 & 0.36 \\
\hline
\end{tabular}

almost the same when the earthquake loads with the intensity of $S_{\mathrm{a}}\left(T_{1}\right)=0.1 \mathrm{~g}$ and $S_{\mathrm{a}}\left(T_{1}\right)=0.2 \mathrm{~g}$. However, when $S_{\mathrm{a}}\left(T_{1}\right)$ turns up to $0.4 \mathrm{~g}$, it can be observed that the structural response of scheme N2 is lower than that of other schemes. The structural response of N3 is lower than that of N4.

5.3. Group $S$. The peak interstory drift ratios of group $S$ under three seismic intensity loads $\left(S_{\mathrm{a}}\left(T_{1}\right)=0.1 \mathrm{~g}, 0.2 \mathrm{~g}\right.$, $0.4 \mathrm{~g}$ ) are $0.28 \% \sim 0.32 \%, 0.61 \% \sim 0.71 \%$, and $1.4 \% \sim 1.58 \%$, lower than those of PDS too. As expected, the response of the structure decreases along with the increasing of the crosssectional size of the extra poles.

\section{Structural Collapse Fragility Analysis}

Collapse fragility functions are fitted based on the IDA results. Structural fragility function presents the relation between seismic intensity and structural fragility, and a collapse fragility curve represents the probability of collapse as a function of ground motion intensity $\left(S_{\mathrm{a}}\left(T_{1}\right)\right.$, in this study). Generally, a structure is considered as safe when its collapse probability is acceptably low during strong earthquakes. FEMA-P695 recommends the acceptably low probability of structural collapse is $10 \%$ or less [41], which means that buildings are considered to be safe when the collapse probability is equal to or less than $10 \%$. Parameters of the fragility function for all the eleven structural cases are fitted using aforementioned IDA results, as shown in Table 5. $S_{\mathrm{a}}\left(T_{1} ; 10 \%\right)$ represents the spectral acceleration at the first-mode period, which causes a $10 \%$ probability of structural collapse. Figure 7 gives the collapse probability of group $\mathrm{A}, \mathrm{N}$, and $\mathrm{S}$, respectively, beside with PDS and SDS under the seismic intensity of interest. To illustrate the support effect better, the fragility curve of $\mathrm{A} 3$ is also shown in Figures $7(\mathrm{~b})$ and $7(\mathrm{c})$.

It can be observed from Table 5 that support schemes improve collapse capacity of the poorly designed structure, as the value of median collapse capacity parameter $\theta$ and
TABLe 5: Parameters of the fragility function.

\begin{tabular}{lcccc}
\hline Case & & $\theta(\mathrm{g})$ & $\beta$ & $S_{\mathrm{a}}\left(T_{1} ; 10 \%\right)(\mathrm{g})$ \\
\hline SDS & & 2.37 & 0.65 & 1.03 \\
PDS & & 1.31 & 0.65 & 0.57 \\
& $\mathrm{~A} 1$ & 2.30 & 0.60 & 1.07 \\
Group A & A2 & 2.32 & 0.63 & 1.05 \\
& $\mathrm{~A} 3$ & 2.39 & 0.63 & 1.08 \\
& $\mathrm{~A} 4$ & 2.32 & 0.67 & 1.00 \\
& $\mathrm{~A} 5$ & 2.34 & 0.63 & 1.05 \\
Group N & $\mathrm{N} 1$ & 2.19 & 0.69 & 0.92 \\
& $\mathrm{~N} 2$ & 2.11 & 0.72 & 0.86 \\
& $\mathrm{~N} 3$ & 2.15 & 0.71 & 0.87 \\
& $\mathrm{~N} 4$ & 2.02 & 0.63 & 0.91 \\
Group S & S1 & 2.11 & 0.75 & 0.82 \\
& S2 & 1.98 & 0.76 & 0.75 \\
& S3 & 1.93 & 0.76 & 0.74 \\
& S4 & 1.92 & 0.70 & 0.80 \\
\hline
\end{tabular}

$S_{\mathrm{a}}\left(T_{1} ; 10 \%\right)$ for PDS is obviously lower than that of supported structures. The change of $\theta$ (median of the fragility function) of support schemes $(1.92 \mathrm{~g} 2.39 \mathrm{~g})$ has a great improvement in seismic collapse capacity compared with PDS $(1.31 \mathrm{~g})$. Moreover, $S_{\mathrm{a}}\left(T_{1} ; 10 \%\right)$ value of the support schemes $(0.8 \mathrm{~g} \sim 1.08 \mathrm{~g})$ increased obviously from PDS (0.57g).

Thirteen support schemes have different effects on improving the collapse resistance of PDS. The change of parameter $\theta$ in Table 5 shows that the collapse resistance of individual schemes under earthquake can be close to or even exceed SDS. For example, $\theta(\mathrm{A} 3)=2.39 \mathrm{~g}$, slightly larger than $\theta$ (SDS). The seismic intensity of $10 \%$ collapse probability of the SDS structure is $1.03 \mathrm{~g}$, which is smaller than A1 (1.07 g), A2 (1.05 g), A3 (1.08 g), and A5 (1.05 g). In terms of parameters $\theta$ and $S_{\mathrm{a}}\left(T_{1} ; 10 \%\right)$, the PDS could meet the structural collapse resistance requirements with proper simple extra pole supporting. Although the structural collapse safety of groups $\mathrm{N}$ and $\mathrm{S}$ is not as good as that of group A, it has been significantly improved compared with PDS.

6.1. Group A. It can be seen from Figure 7(a) that schemes of group A significantly reduce the structural seismic collapse probability of PDS and greatly improve the anticollapse ability of the structure. The fragility curves of group A are very similar to those of SDS, besides case A3 $\left(\alpha=45^{\circ}\right)$ has a lower collapse probability than SDS. In group A, the seismic intensity values leading to a $50 \%$ collapse probability of structures are between $2.30 \mathrm{~g}$ and $2.39 \mathrm{~g}$, and the change rate is less than $5 \%$. However, the earthquake intensity, which leads to a $10 \%$ collapse probability $\left(S_{\mathrm{a}}\left(T_{1} ; 10 \%\right)\right)$, is between $1.0 \mathrm{~g}$ and $1.08 \mathrm{~g}$, and the change rate is less than $10 \%$. These facts indicate that the angle between extra poles and ground $(\alpha)$ has little effect on the support effect on the collapse safety improvement when all the frames are supported with poles' cross-sectional dimension $200 \mathrm{~mm} \times 300 \mathrm{~mm}$.

However, it is worth mentioning that scheme A3 $\left(\alpha=45^{\circ}\right)$ even has a lower collapse probability than SDS. In 


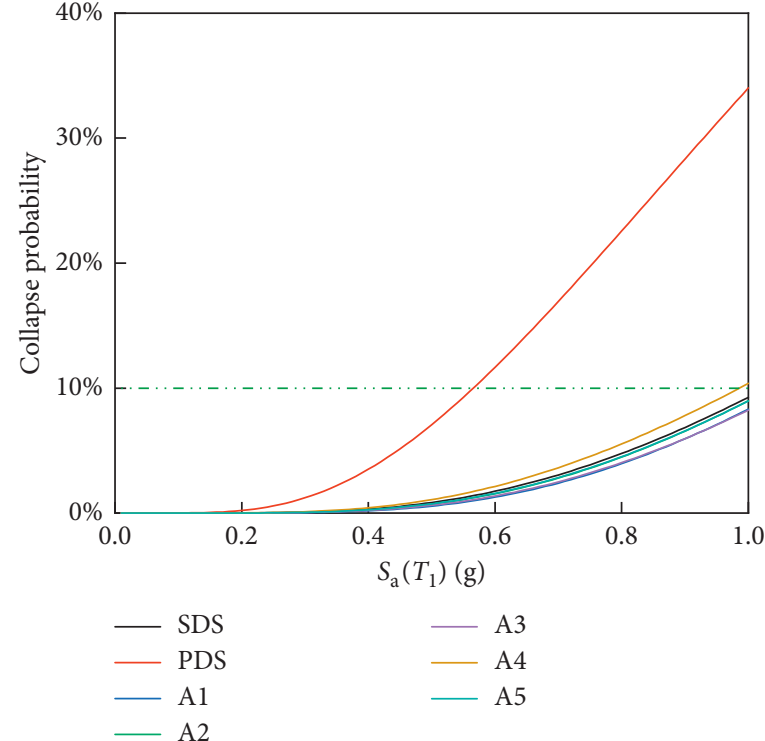

(a)

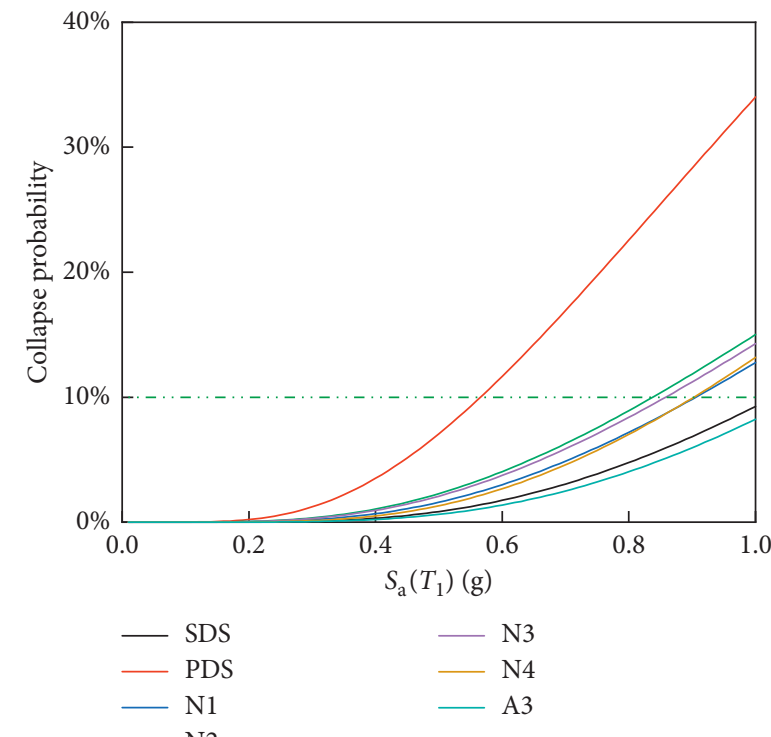

(b)

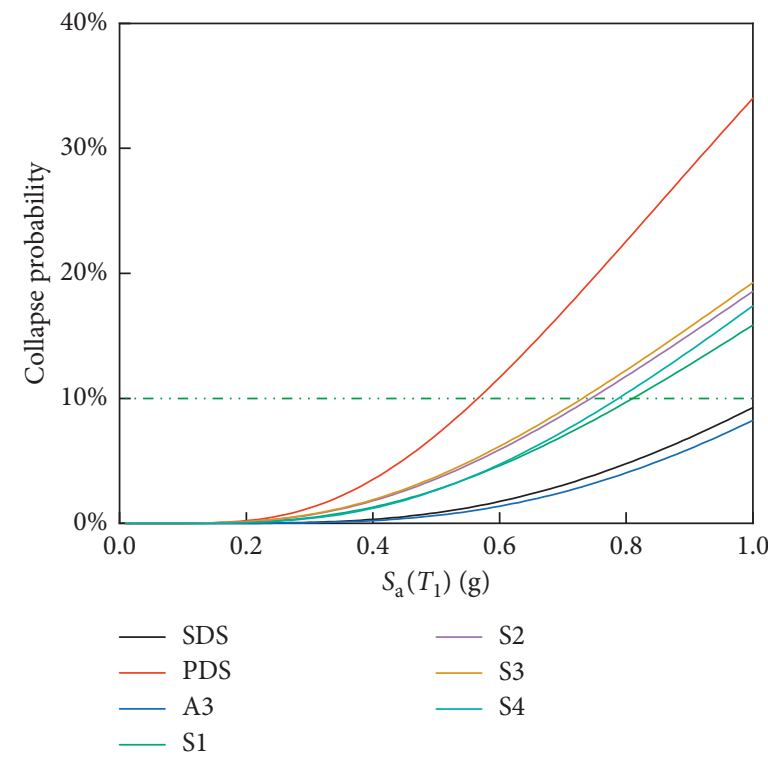

(c)

FIgURE 7: Collapse fragility curves.

terms of the value of $\theta$ and $S_{\mathrm{a}}\left(T_{1} ; 10 \%\right), \mathrm{A} 3\left(\alpha=45^{\circ}\right)$ is the most efficient support scheme in group $\mathrm{A}$.

6.2. Group N. It can be seen from Table 5 that group $\mathrm{N}$ increases $S_{\mathrm{a}}\left(T_{1} ; 10 \%\right)$ from $0.57 \mathrm{~g}$ to $0.86 \sim 0.92 \mathrm{~g}$ and $\theta$ from $1.31 \mathrm{~g}$ to $2.02 \sim 2.19 \mathrm{~g}$. In terms of values of the median collapse capacity parameter $\theta$, scheme $\mathrm{N} 1(\theta=2.19 \mathrm{~g}$, highest of group $\mathrm{N}$ ) is the most efficient scheme in group $\mathrm{N}$, followed by N3, N2, and N4, by turn. While in terms of $S_{\mathrm{a}}\left(T_{1} ; 10 \%\right)$, scheme $\mathrm{N} 1\left(S_{\mathrm{a}}\left(T_{1} ; 10 \%\right)=0.92 \mathrm{~g}\right.$, highest of group $\left.\mathrm{N}\right)$ is the most efficient scheme in group $\mathrm{N}$, followed by $\mathrm{N} 4, \mathrm{~N} 3$, and $\mathrm{N} 2$, by turn. Generally, the seismic collapse safety of group $\mathrm{N}$ is not as well as A3 scheme; the scheme with all frames supported obviously has greater seismic collapse safety improvement than schemes with part frames supported. Figure 7(b) proves that schemes of group $\mathrm{N}$ also significantly decrease the seismic collapse probability of PDS and have an obviously higher probability of collapse than that of A3.

6.3. Group S. Table 5 shows that support schemes in group $S$ increase the median parameter of the structural collapse fragility function which increases from $1.31 \mathrm{~g}$ to $1.92 \sim 1.93 \mathrm{~g}$ and $S_{\mathrm{a}}\left(T_{1} ; 10 \%\right)$ from $0.57 \mathrm{~g}$ to $0.74 \sim 0.82 \mathrm{~g}$. The improvement of the seismic collapse capacity of the structure is quite obvious as well. Figure 7 (c) confirms that group S can effectively improve structural seismic collapse safety of PDS. In addition, the cross-sectional areas of scheme A3 and group $\mathrm{S}$ are, respectively, $\mathrm{C} 0, \mathrm{C} 1, \mathrm{C} 2, \mathrm{C} 3$, and $\mathrm{C} 4$, as shown 
in Table 1. It can be seen that structural seismic collapse capacity decreases with the decrease of the cross-section area of the extra poles as we expected in terms of the median collapse capacity parameter $\theta$. However, the changes of $S_{\mathrm{a}}\left(T_{1} ; 10 \%\right)$ and Figure $7(\mathrm{c})$ show that larger cross-sectional area of the extra poles is not always counted on the lower probability of collapse. $S_{\mathrm{a}}\left(T_{1} ; 10 \%\right)$ of scheme $\mathrm{S} 4$ is larger than that of S2 and S3, and it can be seen from Figure 7 (c) that when seismic intensity $S_{\mathrm{a}}\left(T_{1}\right)<1 \mathrm{~g}$, the structural collapse probability of scheme S4 is obviously lower than that of scheme S2 and S3. Generally, schemes of group S have improved the structural seismic collapse safety of PDS, but there is still a significant gap from SDS.

\section{Dynamic Damage Analysis}

In this study, damage analysis is conducted with two static nonlinear pushover analyses performed, respectively, before and after the time-history dynamic analysis, as mentioned previously. Ground motion record No. 5 (Imperial Valley06, 1979, Chihuahua) in Table 3 is selected as the representative ground motion record to study the dynamic structural damage. The structural damage index under seismic loads with the intensity of interest $(0.1 \mathrm{~g}, 0.2 \mathrm{~g}, 0.3 \mathrm{~g}$, and $0.4 \mathrm{~g}$ in this study) is investigated.

Structural damage indexes of 15 cases in Table 2 under seismic loads with the intensity of $S_{\mathrm{a}}\left(T_{1}\right)=0.1 \mathrm{~g}, 0.2 \mathrm{~g}, 0.3 \mathrm{~g}$, and $0.4 \mathrm{~g}$, respectively, are given in Table 6 . The data show that when $S_{\mathrm{a}}\left(T_{1}\right)=0.1 \mathrm{~g}$, there is almost no structural damage as DI is less than 0.01 . With the increase of seismic intensity, it is found that damage of structures with support is smaller than that of PDS, and the difference of structural damage among different schemes is obvious. Figure 8 illustrates the structural damage indexes of each group under different earthquake intensities. Meanwhile, the DI increases along with IM, especially when $S_{\mathrm{a}}\left(T_{1}\right)$ reaches $0.2 \mathrm{~g}$. It can be obviously seen from Figure 8 that the support schemes can be really helpful to reduce the structural damage under seismic loads, especially when $S_{\mathrm{a}}\left(T_{1}\right)=0.2 \mathrm{~g}$.

7.1. Group A. Figure 8(a) shows the damage index of PDS, SDS, and group A under four different earthquake intensities. As can be seen, the structural damage index is obviously reduced by the support schemes in group A when the earthquake loads with intensity over $0.2 \mathrm{~g}$. Damage index of the PDS is 0.11 when $S_{\mathrm{a}}\left(T_{1}\right)=0.2 \mathrm{~g}$, obviously greater than that of all the structures in group $A(0.01 \sim 0.03)$. When $S_{\mathrm{a}}\left(T_{1}\right)=0.3 \mathrm{~g}$, the damage index of the PDS is 0.19 , while that of all the structures in group $A$ is between 0.12 and 0.13 . When $S_{\mathrm{a}}\left(T_{1}\right)=0.4 \mathrm{~g}$, the damage index of the PDS is 0.28 , while that of all the structures in group $A$ is between 0.16 and 0.18 . Particularly, when $S_{\mathrm{a}}\left(T_{1}\right)=0.2 \mathrm{~g}$, the structural damage index of group $\mathrm{A}$ is even much smaller than that of SDS, which is 0.09 . Generally, schemes in group A have reduced the damage of PDS under seismic loads, and the difference in the reduction of damage between the five schemes in group A is little.
TABLe 6: Damage index.

\begin{tabular}{lccccc}
\hline$S_{\mathrm{a}}\left(T_{1}\right)(\mathrm{g})$ & & 0.1 & 0.2 & 0.3 & 0.4 \\
SDS & & 0.01 & 0.09 & 0.12 & 0.13 \\
PDS & & 0 & 0.11 & 0.19 & 0.28 \\
& $\mathrm{~A} 1$ & 0 & 0.03 & 0.13 & 0.18 \\
& $\mathrm{~A} 2$ & 0.01 & 0.02 & 0.13 & 0.17 \\
Group A & $\mathrm{A} 3$ & 0 & 0.01 & 0.12 & 0.16 \\
& $\mathrm{~A} 4$ & 0 & 0.01 & 0.12 & 0.16 \\
& $\mathrm{~A} 5$ & 0 & 0.02 & 0.13 & 0.17 \\
& $\mathrm{~N} 1$ & 0.01 & 0.01 & 0.13 & 0.16 \\
Group N & $\mathrm{N} 2$ & 0.01 & 0.12 & 0.19 & 0.26 \\
& $\mathrm{~N} 3$ & 0.01 & 0.1 & 0.17 & 0.24 \\
& $\mathrm{~N} 4$ & 0.01 & 0.03 & 0.15 & 0.19 \\
& $\mathrm{~S} 1$ & 0.01 & 0.04 & 0.08 & 0.24 \\
Group S & $\mathrm{S} 2$ & 0.01 & 0.02 & 0.12 & 0.21 \\
& $\mathrm{~S} 3$ & 0.01 & 0.02 & 0.12 & 0.21 \\
& $\mathrm{~S} 4$ & 0.01 & 0.02 & 0.13 & 0.21 \\
\hline
\end{tabular}

7.2. Group N. Figure 8(b) shows the damage index of PDS, SDS, and group $\mathrm{N}$ under four different earthquake intensities. It can be found that the difference in the reduction of structural damage between the four schemes in group $\mathrm{N}$ is quite obvious. While it can be seen that the most efficient scheme in this group is $\mathrm{N} 1$, which is very close to A3. Schemes N2 and N3 are not that helpful to reduce structural damage, as DIs of them are close to PDS.

7.3. Group S. Figure 8(c) shows the damage index of PDS, SDS, and group $S$ under four different earthquake intensities. Schemes in group $S$ have a significant effect on the reduction of structural damage as well. For example, the damage of all structures in group $S(0.02-0.04)$ was much lower than that of PDS when $S_{\mathrm{a}}\left(T_{1}\right)=0.2 \mathrm{~g}$. It should point out that the structural damage index of scheme $S 1$ is even lower than that of SDS when $S_{\mathrm{a}}\left(T_{1}\right)=0.3 \mathrm{~g}$.

\section{Discussion}

The influence of extra pole supporting on structural seismic performance is very obvious; it can reduce the structural response under earthquake and reduce the probability of seismic collapse. What is more, the proper schemes can reduce structural damage effectively.

Comparative study on the angle between extra poles and the horizontal ground (analysis results of group A) shows that smaller the angle $(\alpha)$ is, the smaller the peak interstory drift ratio $\left(\theta_{\max }\right)$ is, but the difference of seismic response $\left(\theta_{\max }\right)$ is little. In addition, the seismic collapse probability of $\mathrm{A} 3$ is the lowest, and the DIs of A3 and A4 are the lowest, so the most recommended angle between extra poles and the horizontal ground $(\alpha)$ is $45^{\circ}$.

Schemes N1 and N2 are both having two out of three frames supported. It is found that the structural response $\left(\theta_{\max }\right)$ is almost the same when the seismic intensity is low $\left(S_{\mathrm{a}}\left(T_{1}\right)=0.1 \mathrm{~g}, 0.2 \mathrm{~g}\right)$. When the seismic intensity increases to $S_{\mathrm{a}}\left(T_{1}\right)=0.4 \mathrm{~g}$, the maximum interstory displacement angle of $\mathrm{N} 1$ is $0.05 \%$ larger than that of N2, and the gap is obviously widened. However, in terms of the seismic collapse probability and DIs, N2 has a better effect than N1 


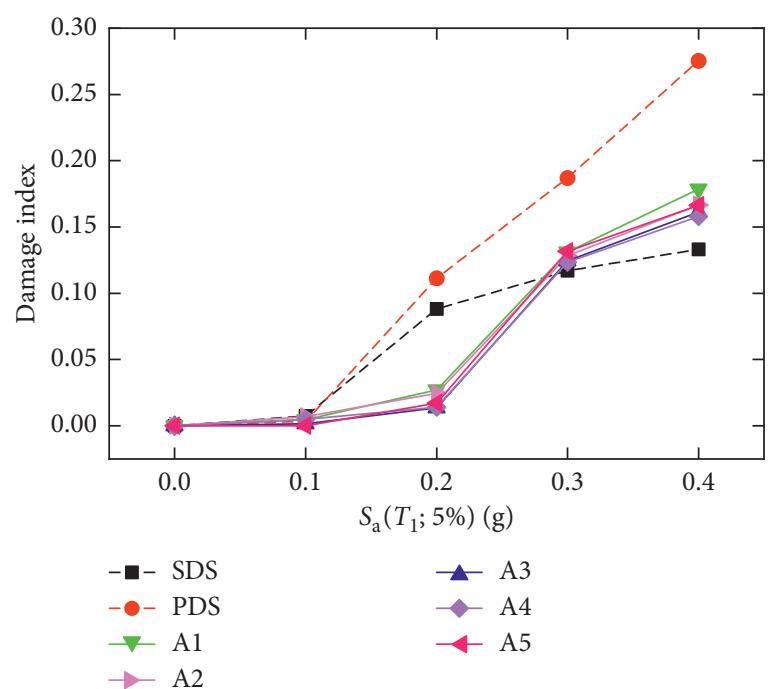

(a)

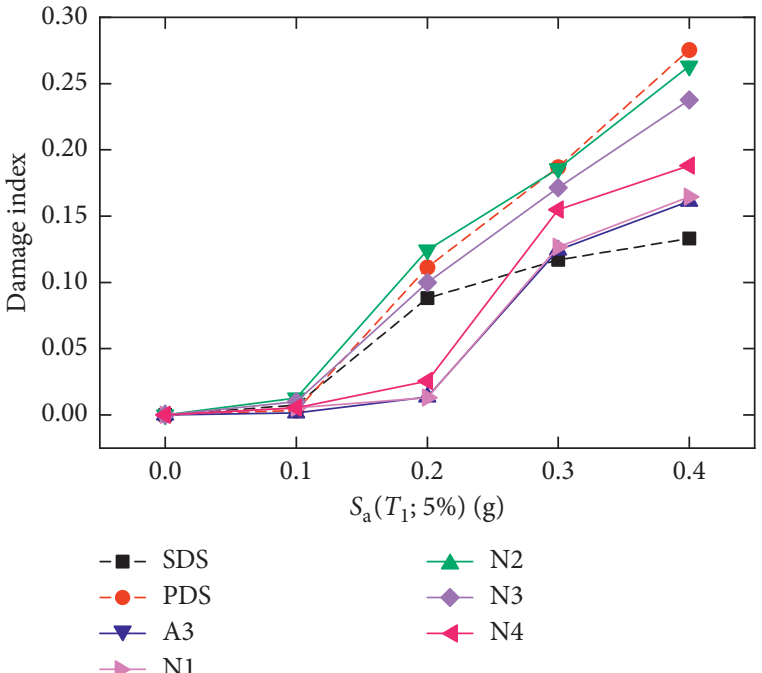

(b)

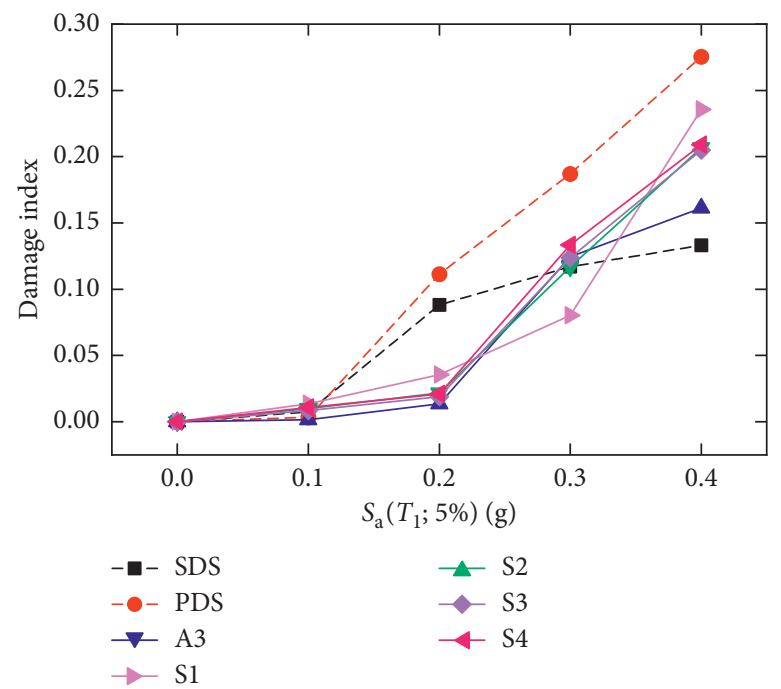

(c)

Figure 8: Damage index after seismic loads with different intensity measures.

because of the lower collapse probability and DIs. It infers that supporting both side frames at the same time can better reduce the structural response than the scheme with one side frame and one middle frame supported, but it is not a more effective way to decrease the collapse probability of PDS.

Schemes N3 and N4 are both having one frame supported. It can be seen the structural response $\left(\theta_{\max }\right)$ is almost the same when the seismic intensity is low $\left(S_{\mathrm{a}}\left(T_{1}\right)=0.1 \mathrm{~g}\right.$, $0.2 \mathrm{~g})$. When the seismic intensity increases to $S_{\mathrm{a}}\left(T_{1}\right)=0.4 \mathrm{~g}$, the maximum interstory displacement angle of $\mathrm{N} 4$ is $0.06 \%$ larger than that of $\mathrm{N} 3$, and the gap is obviously widened. However, in terms of seismic collapse fragility curves in Figure 7(b), N4 has a lower collapse probability than N3. It infers that supporting one side frame can better reduce the structural response, but it is not a more effective way to decrease the collapse probability of PDS.

It can be clearly seen that the scheme with all frames supported (A3) is more effective than only the supporting part of the frames by comparing group $\mathrm{N}$ and scheme A3; as the structural response is smaller, the collapse probability is lower, and the structural damage is smaller.

Analysis results of group $S$ indicate that the larger the cross-sectional area of extra poles, the smaller the structural response and the peak interstory drift ratio $\left(\theta_{\max }\right)$. However, it is found that $S 1$ has the lowest collapse probability under the seismic loads with the intensity of interest, followed by S4, S2, and S3. Collapse safety of the structure of S4 is better than that of S2 and S3.

\section{Conclusions}

This paper constructed numerical analysis models of a lowrising RC building structure, a poorly designed RC building structure with the same geometry size. Three sets of support schemes using extra tilted poles were designed to explore the influence of the support angle between poles and the ground, 
location and the number of poles, and the cross section of poles on the improvement efficiency. Forty ground motion records were selected from the Pacific Earthquake Engineering Research Center (PEER) database to perform nonlinear dynamic analysis. Incremental dynamic analysis was used to perform nonlinear dynamic structural analyses to collect the data for estimating structural seismic collapse fragility. The structural damage index is used to study the dynamic structural damage and the damage reduction effect of the extra devices.

Results of this study imply the following conclusions:

(1) The nonlinear dynamic analysis results show that the extra tilted poles can reduce the seismic response significantly. But, the seismic response of all the supported cases is still greater than SDS. That is because the extra poles improve the collapse safety mainly through the improvement of structural ductility. The improvement of the lateral stiffness and strength by the extra poles is very limited.

(2) Extra tilted poles can improve the seismic resistance of the RC structure effectively. With proper design (such as group A, case A3), the collapse probability even can be lower than the standard designed building. Support schemes increase the value of $S_{\mathrm{a}}\left(T_{1} ; 10 \%\right)$ to $0.74 \sim 1.08$ from 0.57 and increase value of $\theta$ to 1.92 2.39 from 1.31. PDS with support schemes can have a very close value of $S_{\mathrm{a}}\left(T_{1} ; 10 \%\right)$ and $\theta$ to SDS.

(3) Structural dynamic damage is reduced by the extra tilted poles too. Results show that the DI can be reduced to 0.01 (case $\mathrm{A} 3, \mathrm{~A} 4$ ) from 0.11 under earthquake loads with $S_{\mathrm{a}}\left(T_{1}\right)=0.2 \mathrm{~g}$.

(4) When conditions permit, the most recommended support scheme is having all frames supported with the angle between poles and the ground is $45^{\circ}$, considering a seismic response, collapse probability, and dynamic structural damage comprehensively.

(5) Location of the poles placed has a significant effect on collapse safety and dynamic response. When the site condition makes it impossible to have all frames supported, we should choose the side frame/frames to get a lower collapse probability.

(6) Generally, the larger the cross-section size of the poles, the better the improvement of the structure. This study shows that the collapse probability of the supported structure is very close to that of SDS when the cross-section dimension of the poles is $200 \mathrm{~mm} \times 300 \mathrm{~mm}$. But, when the cross-section dimension is reduced to $200 \mathrm{~mm} \times 200 \mathrm{~mm}$, the collapse probability rises rapidly. In this case, the crosssection dimension of poles should not be smaller than $200 \mathrm{~mm} \times 300 \mathrm{~mm}$. Otherwise, the collapse probability cannot meet the standard requirements.

(7) It is well known that building structures should meet the requirements of stiffness, strength, and ductility. The aforementioned results indicate that the extra pole supporting with proper design can improve the structural seismic collapse capacity and reduce the dynamic damage at a certain level. Well, there is still some difference between SDS and the supported structures. So this support scheme with tilted poles can be a temporary measure to improve structural collapse capacity but not a reinforcement measure for long-term use.

\section{Data Availability}

The datasets generated and analyzed during the current study are available from the corresponding author on reasonable request.

\section{Conflicts of Interest}

The authors declare that they have no conflicts of interest.

\section{Acknowledgments}

This research was financially supported by the National Natural Science Foundation of China (no. 51578113) and the National Key Research and Development Program of China (no. 2018YFD1100405).

\section{References}

[1] F. Fiedrich, F. Gehbauer, and U. Rickers, "Optimized resource allocation for emergency response after earthquake disasters," Safety Science, vol. 35, no. 1, pp. 41-57, 2000.

[2] L. Qiao and S. Zhao, Analysis of Seismic Damage of Engineering Structures in Wenchuan Earthquake, Southwest Jiaotong University Press, Chengdu, China, 2008.

[3] C. B. Haselton, A. B. Liel, G. G. Deierlein, B. S. Dean, and J. H. Chou, "Seismic collapse safety of reinforced concrete buildings. I: assessment of ductile moment frames," Journal of Structural Engineering, vol. 137, no. 4, pp. 481-491, 2011.

[4] A. B. Liel, C. B. Haselton, and G. G. Deierlein, "Seismic collapse safety of reinforced concrete buildings. II: comparative assessment of nonductile and ductile moment frames," Journal of Structural Engineering, vol. 137, no. 4, pp. 492-502, 2011.

[5] D. Dominguez-Santos, P. Ballesteros-Perez, and D. MoraMelia, "Structural resistance of reinforced concrete buildings in areas of moderate seismicity and assessment of strategies for structural improvement," Buildings, vol. 7, no. 4, p. 89, 2017.

[6] M. M. Maniyar, R. K Khare, and R. P. Dhaka, "Probabilistic seismic performance evaluation of non seismic RC frame buildings," Structural Engineering and Mechanics, vol. 33, no. 6, pp. 725-745, 2009.

[7] N. Kyriakides, S. Ahmad, K. Pilakoutas, K. Neocleous, and C. Chrysostomou, "A probabilistic analytical seismic vulnerability assessment framework for substandard structures in developing countries," Earthquakes and Structures, vol. 6, no. 6, pp. 665-687, 2014.

[8] K. A. Korkmaz, "Structural risk assessment and mitigation for low- to mid-rise residential buildings in China," Frontiers in Built Environment, vol. 3, p. 37, 2017.

[9] T. Sevil, M. Baran, T. Bilir, and E. Canbay, "Use of steel fiber reinforced mortar for seismic strengthening," Construction and Building Materials, vol. 25, no. 2, pp. 892-899, 2011. 
[10] T. C. Triantafillou and N. Deskovic, "Strengthening of concrete structures with prestressed FRP sheets," ACI Structural Journal, vol. 89, no. 3, pp. 235-244, 1992.

[11] J. P. Moehle, "Displacement-based design of RC structures subjected to earthquakes," Earthquake Spectra, vol. 8, no. 3, pp. 403-428, 1992.

[12] SEAOC Vision 2000 Committee, Performance-Based Seismic Engineering of Building, SEAOC, Sacramento, CA, USA, 1995.

[13] FEMA 445, Next-Generation Performance-Based Seismic Design Guidelines, Federal Emergency Management Agency, Washington DC, USA, 2006.

[14] American Society of Civil Engineers (ASCE), Seismic Rehabilitation of Existing Buildings (ASCE/SEI 41-06), American Society of Civil Engineers, Reston, VA, USA, 2007.

[15] Applied Technology Council (ATC), Seismic performance assessment of buildings (ATC-58), Applied Technology Council (ATC), Redwood City, CA, USA, 2009.

[16] FEMA-P-58-1, Seismic Performance Assessment of Building, Federal Emergency Management Agency, Washington, DC, USA, 2012.

[17] C. C. Mitropoulou, G. C. Marano, and N. D. Lagaros, "Damage index-based lower bound structural design," Frontiers in Built Environment, vol. 4, p. 32, 2018.

[18] GB50010-2010, Code for Design of Concrete Structures, Ministry of Housing and Urban-Rural Development of the People's Republic of China, Beijing, China, 2010, in Chinese.

[19] Y. Liu and J. S. Kuang, "Spectrum-based pushover analysis for estimating seismic demand of tall buildings," Bulletin of Earthquake Engineering, vol. 15, no. 10, pp. 4193-4214, 2017.

[20] H. Krawinkler and G. D. P. K. Seneviratna, "Pros and cons of a pushover analysis of seismic performance evaluation," Engineering Structures, vol. 20, no. 4-6, pp. 452-464, 1998.

[21] GB50011-2010, Code for Seismic Design of Buildings, Ministry of Housing and Urban-Rural Development of the People's Republic of China, Beijing, China, 2010, in Chinese.

[22] X. Zhao, Y. Wu, A. Y. Leung, and H. F. Lam, "Plastic hinge length in reinforced concrete flexural members," Procedia Engineering, vol. 14, pp. 1266-1274, 2011.

[23] T. Paulay and M. J. N. Priestley, Seismic Design of Reinforced Concrete and Masonry Buildings, John Wiley \& Sons, New York, NY, USA, 1992.

[24] F. Mckenna and G. L. Fenves, Open System for Earthquake Engineering Simulation (OpenSees). Pacific Earthquake Engineering Research Center, University of California, Berkeley, CA, USA, 2013.

[25] A. O. Olorunnisola, Design of Structural Elements with Tropical Hardwoods. Design of Structural Elements with Tropical Hardwoods, Springer International Publishing, New York, NY, USA, 2018.

[26] BSI-BS EN 1194, Timber Structures-Glued Laminated Timber-Strength Classes and Determination of Characteristic Values, BSI, London, UK, 1999.

[27] I. Vanzi, G. C. Marano, G. Monti, and C. Nuti, "A synthetic formulation for the Italian seismic hazard and code implications for the seismic risk," Soil Dynamics and Earthquake Engineering, vol. 77, pp. 111-122, 2015.

[28] Standards New Zealand, Structural Design Actions Part 5: Earthquake Actions: New Zealand (NZS 1170.5:2004), Standards New Zealand, Wellington, New Zealand, 2004.

[29] IBC-ICC, International Building Code, International Code Council, Inc., Washington, DC, USA, 2006.

[30] P. Fajfar, T. Vidic, and M. Fischinger, "A measure of earthquake motion capacity to damage medium-period structures," Soil Dynamics and Earthquake Engineering, vol. 9, no. 5, pp. 236-242, 1990.

[31] D. Vamvatsikos and C. A. Cornell, "Incremental dynamic analysis," Earthquake Engineering \& Structural Dynamics, vol. 31, no. 3, pp. 491-514, 2002.

[32] D. Vamvatsikos and C. A. Cornell, "Applied incremental dynamic analysis," Earthquake Spectra, vol. 20, no. 2, pp. 523-553, 2004.

[33] D. Vamvatsikos and M. Fragiadakis, "Incremental dynamic analysis for estimating seismic performance sensitivity and uncertainty," Earthquake Engineering \& Structural Dynamics, vol. 39, no. 2, pp. 141-163, 2010.

[34] R. Villaverde, "Methods to assess the seismic collapse capacity of building structures: state of the art," Journal of Structural Engineering, vol. 133, no. 1, pp. 57-66, 2007.

[35] FEMA, Recommended Seismic Design Criteria for New Steel Moment-Frame Buildings, Federal Emergency Management Agency, Washington, DC, USA, 2000.

[36] J. W. Baker, "Efficient analytical fragility function fitting using dynamic structural analysis," Earthquake Spectra, vol. 31, no. 1, pp. 579-599, 2015.

[37] D. Lallemant, A. Kiremidjian, and H. Burton, "Statistical procedures for developing earthquake damage fragility curves," Earthquake Engineering \& Structural Dynamics, vol. 44, no. 9, pp. 1373-1389, 2015.

[38] F. Zareian and H. Krawinkler, "Assessment of probability of collapse and design for collapse safety," Earthquake Engineering \& Structural Dynamics, vol. 36, no. 13, pp. 1901-1914, 2007.

[39] A. Ghobarah, H. Abou-Elfath, and A. Biddah, "Responsebased damage assessment of structures," Earthquake Engineering \& Structural Dynamics, vol. 28, no. 1, pp. 79-104, 1999.

[40] F. Yang, G. Wang, and Y. Ding, "Damage demands evaluation of reinforced concrete frame structure subjected to near-fault seismic sequences," Natural Hazards, vol. 97, no. 2, pp. 841-860, 2019.

[41] FEMA, FEMA P695-Quantification of Building Seismic Performance Factors, Federal Emergency Management Agency, Washington, DC, USA, 2008. 


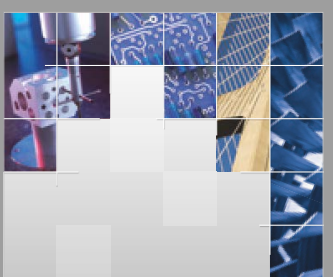

\section{Enfincering}
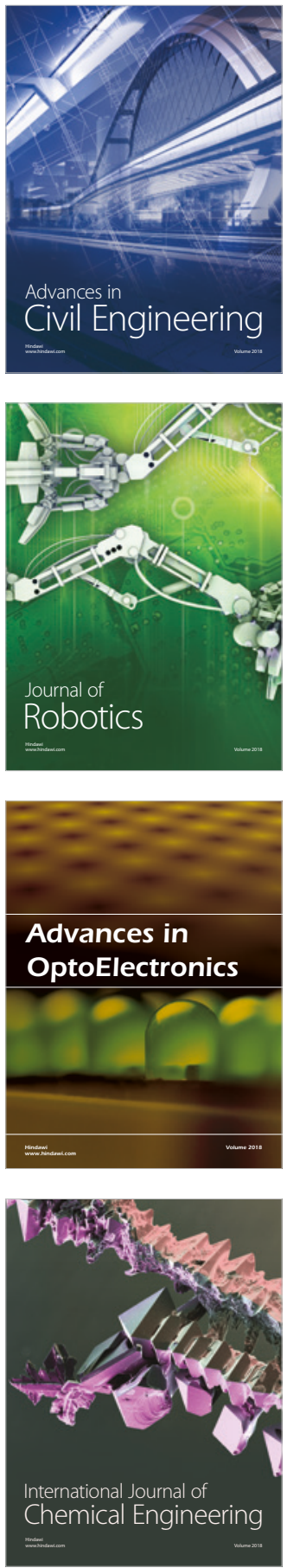

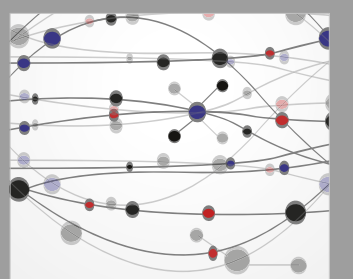

\section{Rotating \\ Machinery}

The Scientific World Journal

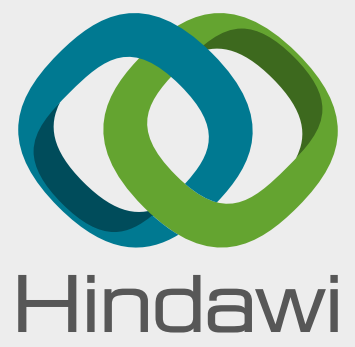

Submit your manuscripts at

www.hindawi.com
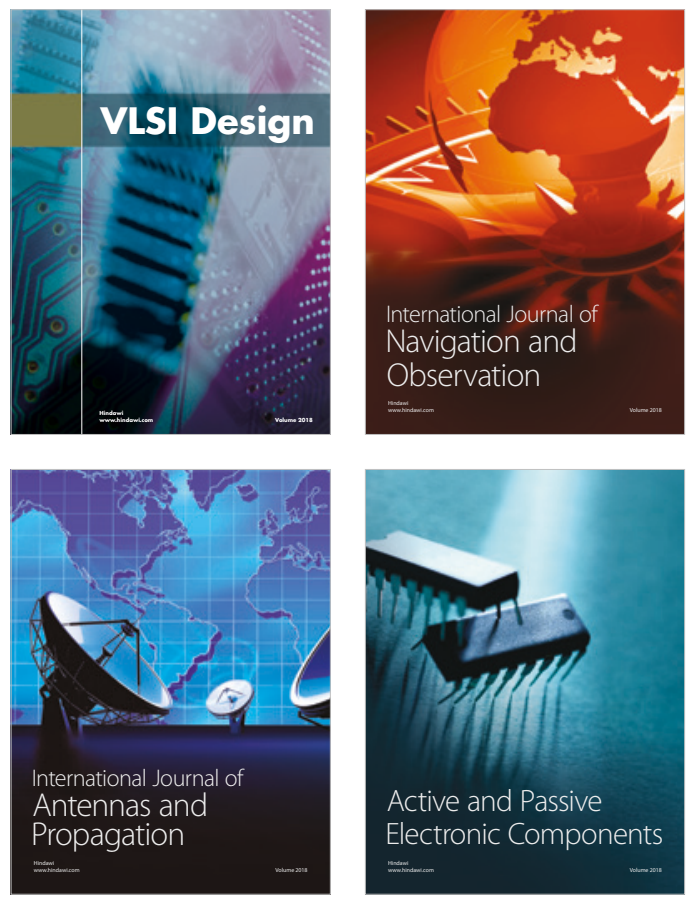
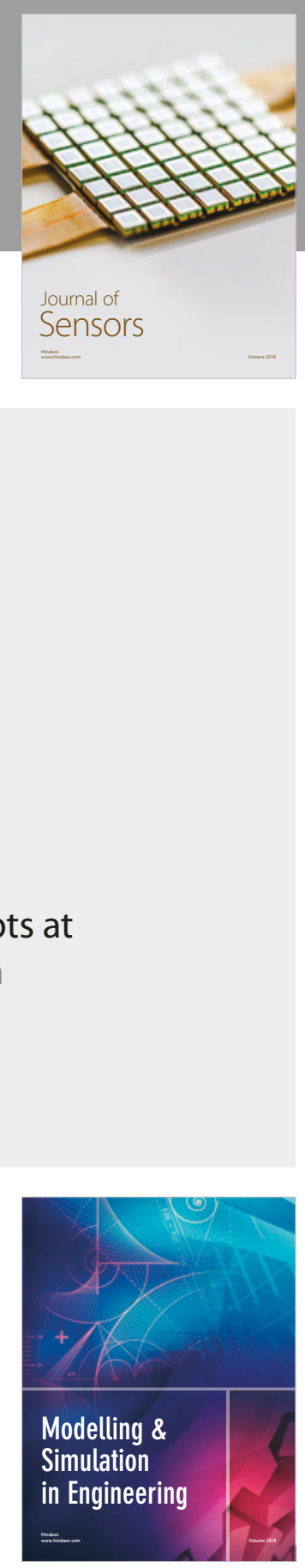

\section{Advances \\ Multimedia}
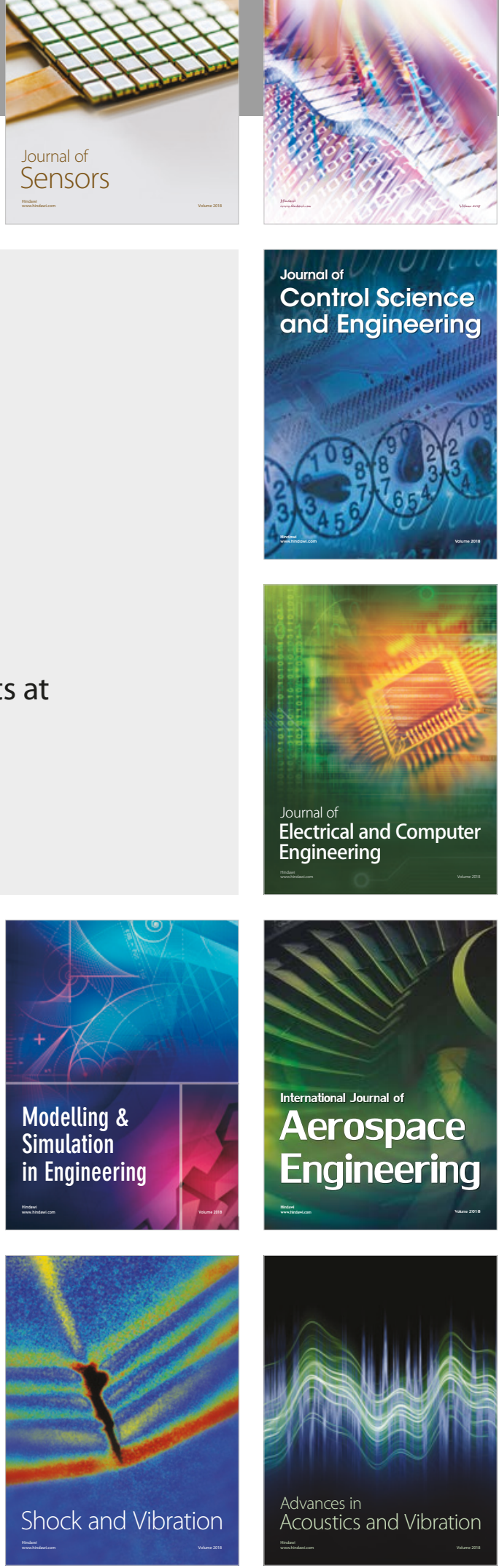